\title{
Contribution of Gut Microbiota to Immunological Changes in Alzheimer's Disease
}

\author{
Lynn van Olst ${ }^{1 *}$, Sigrid J.M. Roks ${ }^{1 \dagger}$, Alwin Kamermans ${ }^{1}$, Barbara J. H. Verhaar ${ }^{2}$, \\ Anne M. van der Geest ${ }^{3}$, Majon Muller ${ }^{2}$, Wiesje M. van der Flier ${ }^{4}$ and Helga E. de Vries ${ }^{1,5}$ \\ ${ }^{1}$ Department of Molecular Cell Biology and Immunology, Amsterdam University Medical Centers, Amsterdam \\ Neuroscience, Amsterdam, Netherlands, ${ }^{2}$ Department of Internal Medicine, Section Geriatrics, Amsterdam UMC, Vrije \\ Universiteit Amsterdam, Amsterdam Cardiovascular Sciences, Amsterdam, Netherlands, ${ }^{3}$ Vrije Universiteit Amsterdam, \\ Athena Institute, Amsterdam, Netherlands, ${ }^{4}$ Alzheimer Center Amsterdam, Department of Neurology, Amsterdam \\ Neuroscience, Vrije Universiteit Amsterdam, Amsterdam UMC, Amsterdam, Netherlands, ${ }^{5}$ Department of Medical \\ Biochemistry, Amsterdam Cardiovascular Sciences, University of Amsterdam, Amsterdam, Netherlands
}

OPEN ACCESS

Edited by:

Daniel Erny,

University of Freiburg Medical Center, Germany

Reviewed by: Agata Mulak,

Wroclaw Medical University, Poland Antoine Louveau,

Cleveland Clinic, United States

*Correspondence: Lynn van Olst I.vanolst@amsterdamumc.nl

${ }^{t}$ These authors share first authorship

Specialty section:

This article was submitted to

Multiple Sclerosis and

Neuroimmunology,

a section of the journal

Frontiers in Immunology

Received: 19 March 2021 Accepted: 14 May 2021

Published: 31 May 2021

Citation:

van Olst L, Roks SJM, Kamermans A, Verhaar BJH, van der Geest AM,

Muller $M$, van der Flier WM and de Vries HE (2021) Contribution of Gut

Microbiota to Immunological

Changes in Alzheimer's Disease.

Front. Immunol. 12:683068.

doi: 10.3389/fimmu.2021.683068
Emerging evidence suggests that both central and peripheral immunological processes play an important role in the pathogenesis of Alzheimer's disease (AD), but regulatory mechanisms remain unknown. The gut microbiota and its key metabolites are known to affect neuroinflammation by modulating the activity of peripheral and brain-resident immune cells, yet an overview on how the gut microbiota contribute to immunological alterations in $A D$ is lacking. In this review, we discuss current literature on microbiota composition in AD patients and relevant animal models. Next, we highlight how microbiota and their metabolites may contribute to peripheral and central immunological changes in $A D$. Finally, we offer a future perspective on the translation of these findings into clinical practice by targeting gut microbiota to modulate inflammation in AD. Since we find that gut microbiota alterations in $\mathrm{AD}$ can induce peripheral and central immunological changes via the release of microbial metabolites, we propose that modulating their composition may alter ongoing inflammation and could therefore be a promising future strategy to fight progression of $A D$.

Keywords: Alzheimer's disease, gut microbiota, neuroinflammation, immune cells, therapeutic intervention, microbial metabolites

\section{INTRODUCTION}

Alzheimer's disease (AD) is a neurodegenerative disorder of which the prevalence and disease burden are increasing simultaneously with an aging population $(1,2)$. Extracellular amyloid-beta (A $\beta$ ) deposition and intracellular accumulation of hyperphosphorylated tau are the primary neuropathological hallmarks of $\mathrm{AD}$ (3), but increasing attention addresses an additional role of distorted immune responses, although underlying mechanisms remain unknown $(4,5)$.

Gut microbiota are important for peripheral and central immune homeostasis (6). Species of microbiota and their metabolites can induce peripheral immune activation and contribute to a systemic immune response (7). Moreover, they can modulate integrity of the blood-brain barrier 
(BBB) (8), which regulates migration of immune cells into the brain (5). In addition, the production of certain metabolites by gut microbiota is linked to the maturation and function of microglia, the CNS resident immune cells (9).

Over thousands of microbial taxa are present in the adult gastrointestinal tract (GI) where interaction takes place between the host, microbial antigens, and environmental factors $(1,10)$. Most of these belong to the gram-negative phylum Bacteroidetes (1, $11-15)$ and the gram-positive phylum Firmicutes $(1,11-14,16)$ with a smaller proportion of gram-positive Actinobacteria (11, 14, 17), and gram-negative Proteobacteria $(14,18)$ and Veruccomicrobia $(12$, 19). Within the two dominant phyla, abundant genera include Bacteroides, Clostridium, Faecalibacterium, Roseburia and Eubacterium (11, 12, 14). Alterations in microbiota composition occur with increasing age (7), starting around 65 years and include an increase in Bacteroidetes and a decrease in Firmicutes (20, 21).

Gut microbiota can affect host immunity via the release of metabolites and toxins. Microbial misbalance can lead to systemic inflammation in the gut and affect the gut barrier function, increasing permeability and the entry of bacteria, metabolites and toxins into the circulation (22) (Figure 1). Interestingly, gut permeability was recently reported to be increased in a cohort of dementia patients together with the occurrence of systemic inflammation (23). Lipopolysaccharide (LPS) is a pro-inflammatory endotoxin found in the outer membrane of gram-negative bacteria like Bacteroidetes (15, 24, 25). Besides LPS, some gram-negative species also excrete polysaccharide A (PSA), which has an anti-inflammatory potential $(7,26-28)$. Other metabolites that predominantly exert immunoregulatory properties are short-chain fatty acids (SCFAs), of which butyrate in particular is known to be produced by species within Firmicutes, mainly within clusters of the Clostridia class (16, 29-31).

During adult life, microbiota composition can be influenced by different factors such as diet $(2,32,33)$, environment (34), body mass index (BMI) (34), cholesterol (34), lifestyle factors such as smoking and exercise (32), drug use (32), and ethnicity $(35,36)$. As such, microbiota components differ greatly between individuals (37). Despite this variation, a common set of microbial taxa can be found across individuals with diverse dietary habits, geographic origin and ethnicity, referred to as the "core microbiome" (12, 38-40). The core microbiome (11, 12 ) is essential for microbial functions even if not carried out by the same group of microbes (10) and depends on the expression

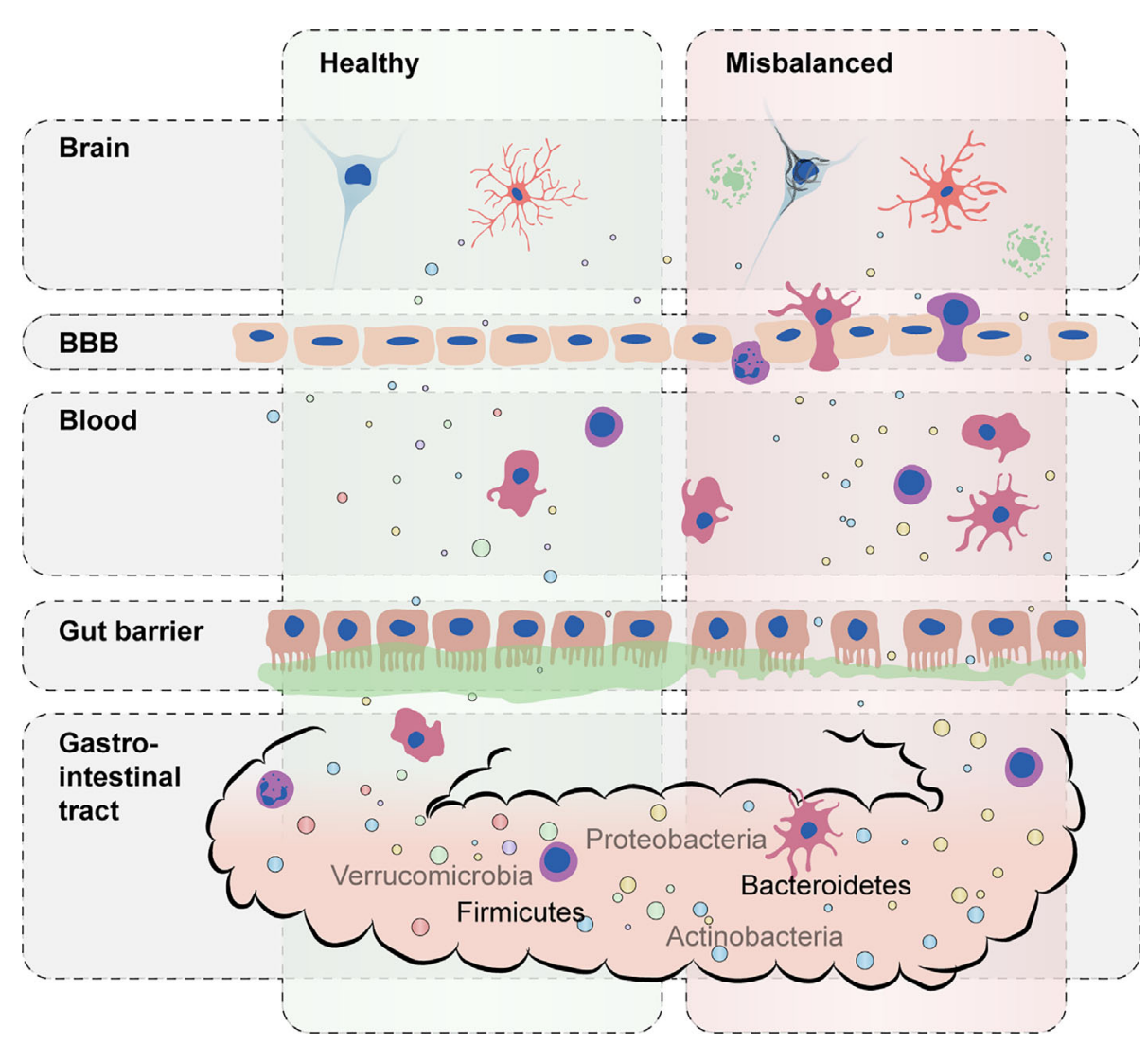

FIGURE 1 | Schematic representation of the impact of a misbalanced gut microbiota on host immunity. A balanced composition of gut microbiota with a high diversity of commensal bacteria carrying out essential microbial functions supports healthy immune responses (left). During microbiota misbalance (right), excessive proinflammatory cytokines and bacterial toxins (e.g., lipopolysaccharide) can lead to disruption of gut permeability and blood-brain barrier (BBB) integrity. Distorted immune responses in the brain can further accelerate and worsen AD-associated pathology such as A $\beta$ and tau accumulation. 
of specific combinations of microbial genes, together with metabolic processes and regulatory pathways. Hence, higher diversity in microbiota composition is associated with better health (41).

Aging is the most important risk factor for AD. During aging, the gut microbiota composition decreases in diversity and stability (42). It has been postulated that these changes may evoke hyperstimulation of the immune system resulting in persistent, low-grade inflammation (43), referred to as "inflammaging" (4), a phenomenon observed in the elderly. In addition, decreased immune function, or 'immunosenescence', is a hallmark of aging. Both inflammaging and immunosenescence contribute to aging of the peripheral immune system, which is associated with higher susceptibility to infection, increased risk of autoimmune diseases and impaired cognitive function $(4,43)$.

In this literature review, we will discuss gut microbiota alterations in both animal model and human studies of AD. Altered microbial taxa and associated metabolites will be described in relation to changes in immune and BBB function. Finally, we will elaborate on possible strategies to target gut microbiota to restore immune homeostasis in $\mathrm{AD}$.

\section{MICROBIOTA COMPOSITION IN AD PATIENTS AND AD ANIMAL MODELS}

\section{Animal Studies}

Various studies have investigated gut microbiota composition in AD mouse models (Supplementary Table 1) (44-55), most in the context of A $\beta$ pathology (44-50, 52-55). Microbial taxa described by three or more studies are shown in Figure 2, while Supplementary Table 2 demonstrates all altered taxa in $\mathrm{AD}$ mouse models compared to wild type (WT). All studies observed changes in microbiota composition at one or more taxonomic levels in mouse models of AD compared to WT, although very few alterations were mentioned at species level (only shown in Supplementary Table 2).

Studies that investigated changes in microbiota composition during the disease course in animal models found that Firmicutes and Bacteroidetes abundance both increased and decreased compared to levels in the WT $(48,53,54)$. Butyrate producers like the family Lachnospiraceae reduced during pathology in $\mathrm{AD}$ mice of both sexes while Roseburia, a genus within Lachnospiraceae, increased over time in male AD mice (54).

Both higher $(44,49,52)$ and lower $(45,51)$ abundance was reported of the phylum Firmicutes in AD mouse models. Families and genera that contain butyrate-producing species like the family Lachnospiraceae $(49,51,52)$ and the genus Roseburia (50-52) were also both increased and reduced in $\mathrm{AD}$ mice compared to WT. Notably, the butyrate-producing genus Ruminococcus was either unchanged or decreased (46, 47, 49). Similar to the abundance of and within Firmicutes, higher (45, $51)$ and lower $(44,49,52)$ abundance was reported of the LPScontaining phylum Bacteroidetes and of its families and genera $(46,48,49,51,52,54,55)$. Only the genus Odoribacter was either unchanged or increased $(46,53)$.
The different findings regarding microbiome alterations in $\mathrm{AD}$ mouse models in the aforementioned studies appear to be independent of age, diet and the type of model, which was either based on A $\beta$ pathology in the APP/PS1 $(45-50,52,54,55)$, 5XFAD $(44,53)$ and Tg2576 models $(54)$, or on tau pathology in the P301L model (51). Divergent results in microbiota composition can be a result of the use of male or female mice. First, because microbiota composition in male and female mice is under the influence of sex-specific hormones $(56,57)$ and second, because $\mathrm{AD}$ pathology manifest itself differently between sexes. Studies using only male mice $(44,49,52)$ showed a reduction in Bacteroidetes and an increase in Firmicutes in AD mouse models, while studies using both males and females varied in their results $(45,51,53)$. At each age, the ratio of Firmicutes/Bacteroidetes remained lower in $\mathrm{AD}$ than in WT mice in females (48), suggesting that females more often show an increase in Bacteroidetes and a reduction in Firmicutes as opposite to male AD mice. Gram-negative families such as Bacteroidaceae are both increased and reduced in male mice in relation to $\mathrm{AD}(46,49,52,55)$, but more often increased in females $(48,54)$. Families that encompass butyrateproducers like Lachnospiraceae $(49,52)$ show increase in male mice, while studies that included females or both sexes demonstrated a decrease $(51,54)$. Microbiota alterations in the gram-negative genus Bacteroides and butyrate-producing genus Roseburia across different studies seem less sex-specific, although one study demonstrated an increase in Bacteroides in females specifically, while males show an increase in Roseburia (54). Since the large majority of studies use either male mice or a combination of males and females, it is possible that the overall results are more specific for males than they are for females.

Altogether, it seems that various alterations in microbiota composition are associated with pathology and disease progression in $\mathrm{AD}$ animal models. This suggests that general microbiota misbalance, rather than alterations in specific taxa, is characteristic for $\mathrm{AD}$.

\section{Human Studies}

So far, only three studies have directly compared gut microbiota composition in AD patients to controls (58-60) and one studied microbiome associations with amyloid pathology (61) (Supplementary Table 3).

Both an increase (58) and a slight decrease (59) in abundance of the phylum Bacteroidetes was reported in AD patients (Figure 3). All species within the phylum Bacteroidetes are gram-negative and contain the toxin LPS in their outer membrane $(15,24,25)$. Higher circulating levels of LPS were associated with increased $\mathrm{A} \beta$ deposition in elderly patients with cognitive complaints (62). Increased abundance was detected in most genera within Bacteroidetes and most of its species, including B. fragilis (60), which produces polysaccharide A (PSA) (7). Interestingly, $B$. fragilis was decreased in cognitively impaired patients that were A $\beta$-positive compared to healthy subjects (61).

Abundance of the phyla Firmicutes was both reduced (58) and unchanged (59) in AD patients. Within Firmicutes, a reduction was seen in the family Lachnospiraceae $(59,60)$ the genus Roseburia (60) and the genus Eubacterium (60), which all 


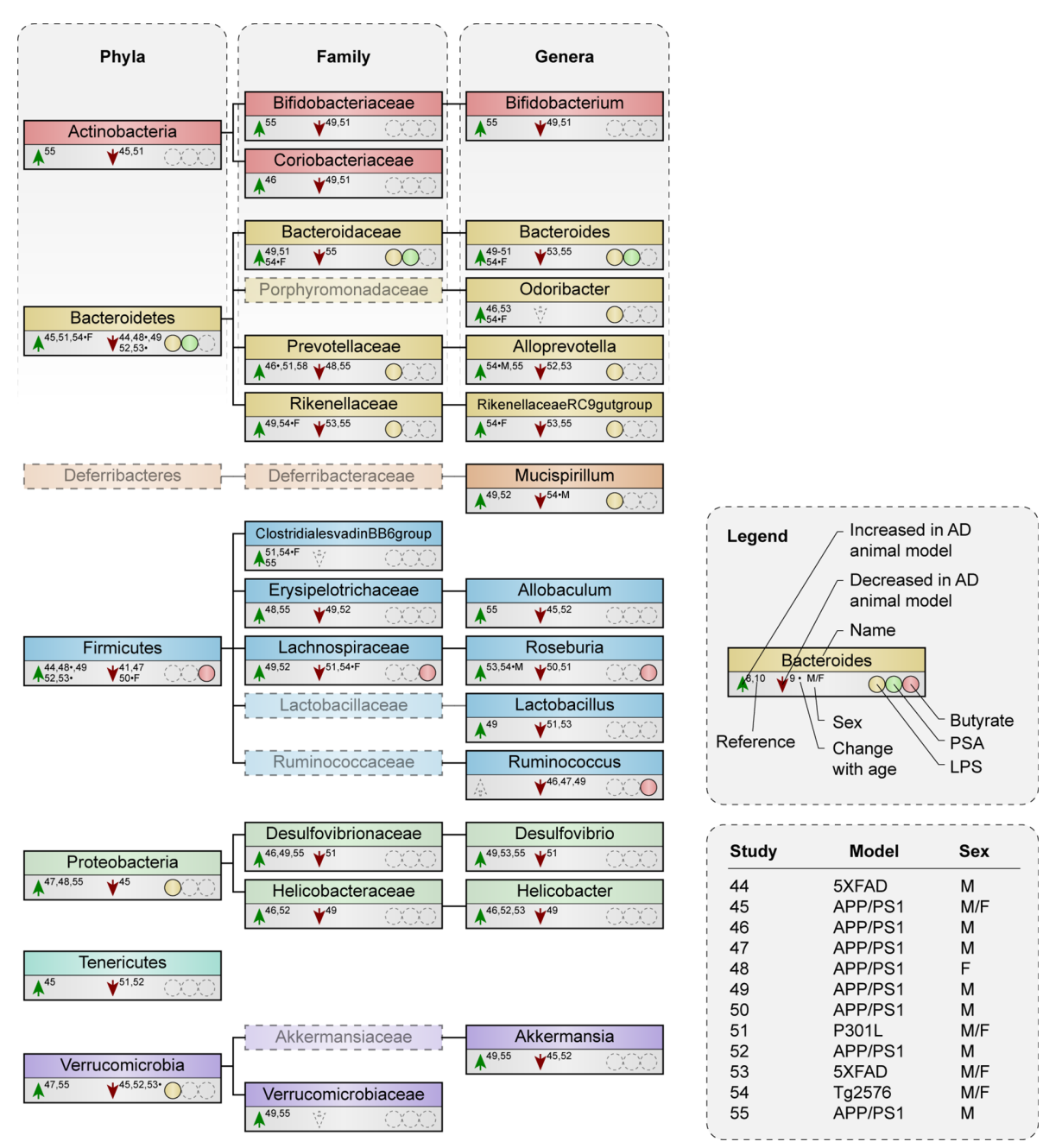

FIGURE 2 | Microbial taxa are altered in AD mouse models compared to WT mice. Phylogenetic representation at phylum, family and genus level of microbial taxa described by three or more animal studies. Animal studies are represented that either compare microbiota composition between AD and WT mice at certain age point(s), or that examine alterations with increasing age in AD mice compared to WT. Arrows indicate an increase or decrease in abundance of a certain taxa in AD mouse models compared to WT. * indicates a result was observed in AD mice with increasing age, but not in WT. F or M show a change that was only seen in females or males respectively, if both were included in one study. Presence or excretion of toxin lipopolysaccharide (LPS; yellow) and metabolites polysaccharide A (PSA; green) and butyrate (red) is indicated, as well as the used animal model and sex of the animals used per study.

harbor species that produce the metabolite butyrate. At species level, butyrate-producers like $R$. hominis, F prausnitzii, E. rectale and $E$. hallii were lower abundant in AD patients (60). Interestingly, butyrate levels in plasma negatively associated with $A \beta$ deposition in cognitively impaired patients (62).

The deposition of $A \beta$ in cognitively impaired patients positively associates with the abundance of the gram-negative genus Escherichia/Shigella, while the butyrate-producing species $E$. rectale negatively relates to $A \beta$ deposition in these patients, both as compared to $A \beta$-negative cognitively impaired patients and healthy controls (61). In addition, differences in variation of microbial taxa within an individual, which is also called $\alpha$ diversity and associates with better health (41), was decreased in $\mathrm{AD}$ patients (58).
Available evidence regarding microbiota composition in patients with $\mathrm{AD}$ faces several limitations, including small sample sizes and limited data on and adjustment for dietary intake and other relevant confounding factors, such as co-morbidity, use of medication and lifestyle. Only two of the aforementioned studies $(60,61)$ reported microbiota composition at species level. Few studies related the observed differences between groups to disease biomarkers and severity, such as cerebral spinal fluid (CSF) or PET biomarkers for A $\beta$ and tau, MRI characteristics or cognitive functioning. Therefore, results should be interpreted with caution. Limited human data points towards higher abundance of gram-negative species containing LPS while species that produce the metabolite butyrate were decreased. Besides, phyla, families and genera 


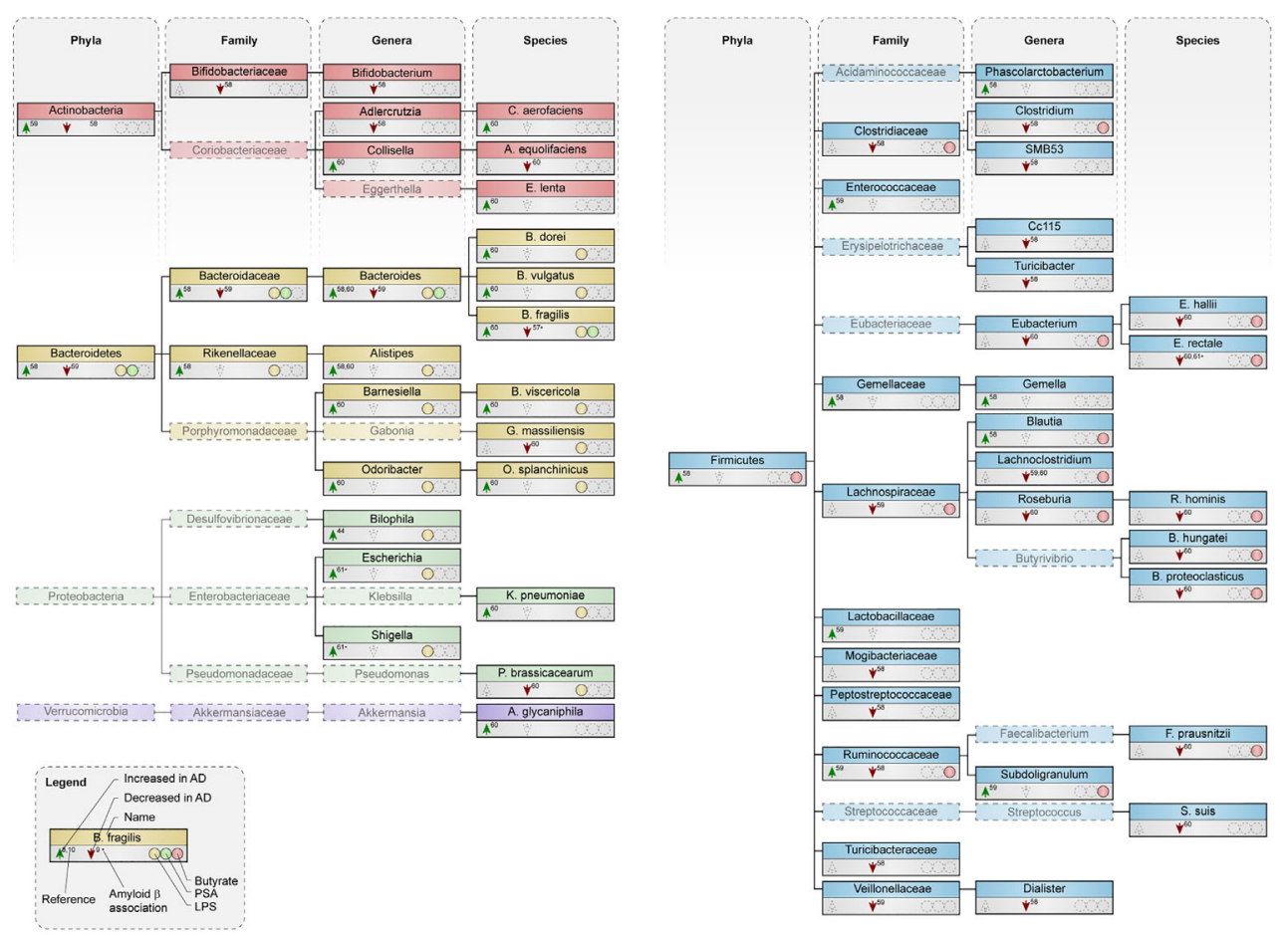

FIGURE 3 | Microbial taxa are altered in AD patients compared to control subjects. Phylogenetic representation at phylum, family, genus and species level of microbial taxa in human studies. Arrows indicate an increase or decrease in abundance of a certain taxa in AD patients compared to healthy controls. ${ }^{*}$ depict changes associated with amyloid pathology in cognitively impaired patients. Presence or excretion of toxin lipopolysaccharide (LPS; yellow) and metabolites polysaccharide A (PSA; green) and butyrate (red) is indicated.

encompassing these LPS-containing and butyrate-producing species were also mostly increased and decreased respectively.

\section{MICROBIOME-IMMUNE INTERACTIONS}

Bacteroidetes and Firmicutes make up the largest portion of the adult microbiota and showed most changes in abundance in $\mathrm{AD}$ patients and in relevant animal models. Here, we discuss how species of Bacteroidetes and Firmicutes and their metabolites cause activation or inhibition of peripheral and central immune cells and how they affect function of the BBB (Figure 4).

\section{Gram-Negative Bacteria}

Bacteria within the phylum Bacteroidetes are gram-negative and contain LPS $(15,24,25)$. LPS can induce systemic inflammation via Toll-like receptor (TLR)-4 signaling $(15,24,25)$ and promotes the secretion of proinflammatory cytokines like interleukin 1 and 6 (IL-1 and IL-6) and tumor necrosis factor $\alpha$ (TNF- $\alpha$ ) (63). IL- 1 and IL-6 are required for differentiation of T-helper 17 (Th17) cells (64), which via proinflammatory cytokine release and their action on neurons via the Fas/Fasligand apoptotic pathway, are thought to contribute to neuroinflammation and neurodegeneration in $\mathrm{AD}$ (65). In addition, LPS of the species $B$. fragilis induced signaling via nuclear factor kappa-light-chain-enhancer of activated B cells $(\mathrm{NF}-\mathrm{\kappa B})$ in human neuronal-glial co-cultures, an important pathway in inflammatory neurodegeneration (66). Moreover, increased abundance of the genus Bacteroides positively associated with cerebrospinal fluid (CSF) levels of chitinase 3 like protein 1 or YKL-40, which is a marker for microglial and astroglial cell activation (58). Increases in species of Bacteroidetes might contribute to LPS transport from the intestines to the brain, adding to AD pathology $(33,67)$. Interestingly, LPS has been found at higher levels in the parenchyma and vessels of $A D$ brains compared to aged-matched controls, and co-localized with $A \beta$ plaques around blood vessels (67).

LPS has also been described to increase P-glycoprotein (P-gp) expression at the intestinal epithelial barrier (68) and the BBB (69) but to reduce its activity $(68,69)$. P-gp is a protein highly expressed at the brain endothelium $(70,71)$, where it functions as an efflux transporter, and is involved in the clearance of $A \beta$ across the $\mathrm{BBB}$ (70-72). In AD, P-gp expression and function at the $\mathrm{BBB}$ is decreased $(66,73-75)$, contributing to $\mathrm{A} \beta$ accumulation in the brain $(74,75)$. Interestingly, fecal supernatants isolated from $\mathrm{AD}$ patients decreased expression of P-gp in an intestinal epithelial monolayer culture, compared to supernatants from control subjects and elders with other dementia types (60). The expression of P-gp was influenced by the abundance of several gram-negative Bacteroides species. High 


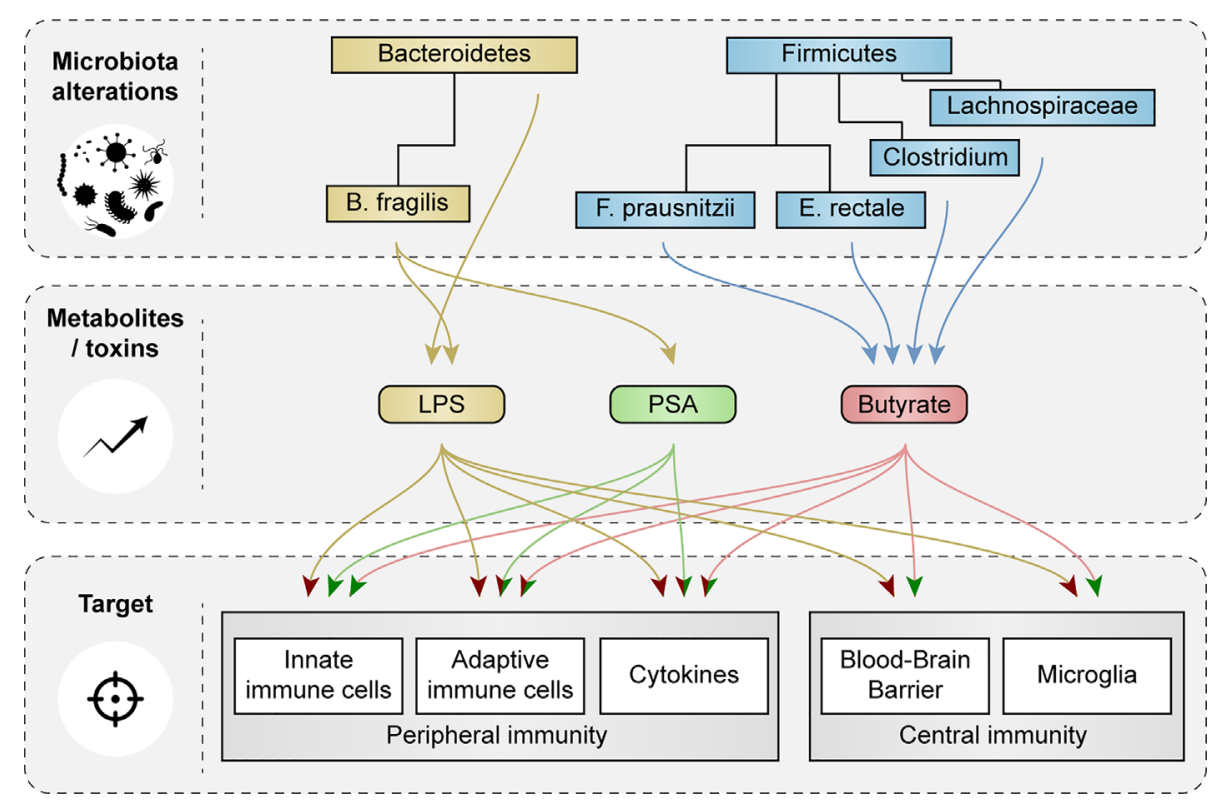

FIGURE 4 | Schematic representation of the effects of microbial metabolites and toxins on peripheral and central immunity and blood-brain barrier function. Impact of microbial metabolites and toxins, that were changed in AD patients and in relevant animal models, on peripheral and central immune cells, cytokine secretion and blood-brain barrier (BBB) function are showed. Red arrow heads indicate a pro-inflammatory effect or loss of BBB integrity, green arrow heads indicate tolerogenic effects and improvements in BBB function.

levels of the species $B$. dorei increased P-gp expression while increased abundance of $B$. fragilis and $B$. vulgatus correlated to decreased expression of P-gp (60).

In addition, the presence of meso-diaminopimelic acid (meso-DAP) in the peptidoglycan layer of the bacterial cell wall, which is part of all gram-negative and some grampositive bacteria, is recognized by the nucleotide-binding oligomerization domain-containing protein 1 (NOD1) (76). Excretion or translocation of gram-negative peptidoglycan increased activity of bone marrow-derived neutrophils via NOD1 receptor signaling (77).

\section{Gram-Negative Bacteria: PSA Producers}

Polysaccharide A (PSA) is a capsular carbohydrate that specifically derives from the gram-negative species $B$. fragilis. PSA from $B$. fragilis promotes regulatory immune responses via binding to TLR-2 (26-28), including the induction of dendritic cells (DCs) and regulatory $\mathrm{T}$ cells (Treg) (26-28) and the secretion of IL-10 $(28,78)$, together with subsequent inhibition of Th17 cells $(26,27)$ and suppression of IL-17 production $(79)$. Colonization of germ-free (GF) mice with PSA-producing $B$. fragilis led to an expansion of $\mathrm{CD}^{+} \mathrm{T}$ cell levels in the spleen and restored the Th1/Th2 cytokine balance of GF mice by reducing IL-4 production and restoring interferon $\gamma$ (IFN- $\gamma$ ) expression (80). Interestingly, another study that investigated PSA-mediated stimulation of $\mathrm{CD}^{+} \mathrm{T}$ cells found that cells responding to PSA displayed an unusual combination of pro-inflammatory cytokines (IFN- $\gamma$, TNF- $\alpha$, IL-6 and C-X-C motif chemokine ligand 10) and anti-inflammatory surface receptor expression
(Lag3, Tim3, Pd1) that was mainly driven via the interferon signaling pathway (81). Hence, the immunological response to PSA exposure is highly context dependent and cannot be considered simply regulatory or pro-inflammatory.

\section{Butyrate-Producing Bacteria}

Short-chain fatty acids (SCFAs) promote gut integrity and play an important role in both physiological and pathological conditions (82-84). The most abundant SCFAs are acetate, butyrate and propionate, of which butyrate is particularly essential in the gut, as it is the most important metabolic substrate required for colonocyte proliferation and differentiation $(82,85)$. Butyrateproducing bacteria are widely distributed amongst the grampositive phylum Firmicutes (16). Two of the most important butyrate-producing species are F. prausnitzii and E. rectale (29, 86), which exert different effects on peripheral immunity, including the induction of Treg cells $(87,88)$ and inhibition of NF- $\kappa B$ signaling in the intestinal epithelium (89). Additional butyrate producing taxa can be found within other bacterial families, mostly in Lachnospiraceae (see Figures 2 and 3) (90-98)

Butyrate, like other SCFAs, exerts its effects by acting as an histone deacetylase (HDAC) inhibitor (99) and via G-protein receptor (GPCR) signaling (29), which can both lead to inhibition of the NF- $\kappa B$ signaling pathway (100-103). Butyrate-mediated inhibition of HDAC signaling downregulated inflammatory mediators IL-6, IL-12 and nitric oxide synthase 2 (NOS2) in LPS-treated macrophages in vivo, and in vitro (31). Furthermore, butryate-induced GPCR signaling increased IL-10 expression in splenic dendritic cells (DCs) and macrophages in vitro (30) and 
enhanced plasma IL-10 levels in vivo (104). DCs and macrophages cultured with butyrate had increased potency to induce differentiation of Treg cells $(30,104-107)$ and promoted IL-10 production by $\mathrm{CD}^{+} \mathrm{T}$ cells, while decreasing levels of IL-17 (30). Butyrate-induced Treg differentiation in vitro was dependent on transforming growth factor $\beta 1$ (TGF- $\beta 1$ ) (107). Notably, butyrate administration in rats reduced IL-6, IL-17 and IL-23 levels and increased levels of TGF- $\beta$ in the plasma (104). DCs exposed to butyrate could also suppress differentiation of naïve $\mathrm{T}$ cells into pro-inflammatory IFN- $\boldsymbol{\gamma}$ producing $\mathrm{T}$ cells (105). Butyrate also reduced the production of TNF- $\alpha$ and cytokine-induced neutrophil chemoattractant (CINC) $2 \alpha \beta$ and nitric oxide (NO) in LPS-treated rat neutrophils in vitro (99).

However, a high dose of butyrate induced IFN- $\gamma$ and T-bet expression, both associated with a Th1 phenotype, in $\mathrm{CD}^{+} \mathrm{T}$ cells cultured under Treg cell inducing conditions (107). Unlike the induction of Treg cells, induction of these Th1 associated factors was not dependent on TGF- $\beta 1$. Under Th17-polarizing conditions, butyrate inhibited ROR $\gamma \mathrm{t}$ and IL-17A but induced IFN- $\gamma$, while under Th2-polarizing conditions, butyrate decreased expression of GATA3 and IL-4 and induced IFN- $\gamma$. The upregulation of IFN- $\gamma$ under these conditions is dependent on the expression of T-bet. In addition, butyrate upregulated IFN- $\gamma$ in a concentration dependent manner in unpolarized $\mathrm{T}$ cells (107). As such, it has been proposed that butyrate might exert its pro-inflammatory potential in an inflammatory context, while it shows anti-inflammatory effects under homeostatic conditions (107). Still, most evidence points to butyrate as a potent anti-inflammatory SCFA both in vivo and in vitro.

\section{IMMUNE-AD ASSOCIATIONS}

While $\mathrm{AD}$ pathology was long considered to be driven mainly by $\mathrm{A} \beta$ and tau pathology, accumulating evidence shows that dysfunctional neuro-immunological responses considerably contribute to $\mathrm{AD}$ pathogenesis and might even be a driving factor (5). Rare genetic variants associated with $\mathrm{AD}$ are often highly expressed in microglia, including the triggering receptor expressed on myeloid cells 2 (TREM2) (108). Rare variants of TREM2 are associated with a two- to threefold increase in risk of $\mathrm{AD}$ development (109). Besides, the role of the immune system in $\mathrm{AD}$ is not limited to the brain, but also involves peripheral immune signaling $(4,5,110)$. Accordingly, blood-derived leukocytes were identified in the brain of $\mathrm{AD}$ patients and AD animal models (111113), and infiltration of these peripheral immune cells into the brain during disease pathogenesis can be facilitated by an increase in BBB inflammation and enhanced permeability (114).

Through the release of cytokines, complement proteins and major histocompatibility complex (MHC) class I proteins, peripheral immunity can affect CNS homeostasis (115). Besides, factors that exert their functions in the CNS, like neurotransmitters, are involved in the mediation of immune responses through corresponding receptors on innate and adaptive immune cells (116-118). In addition, the CNS can control systemic immune responses via the vagus nerve (119), and the sympathetic branch of the autonomic nervous system can influence intestinal immunity and homeostasis (120). Activation of the HPA axis and subsequent release of glucocorticoids also greatly affects immune responses (121). The recently discovered brain lymphatic system (122-124) and the regulation of immune cell trafficking across the BBB (125) further contribute to communication between the peripheral immune system and the CNS (125). As discussed, microbiota can exert different effects on central and peripheral immunity via their metabolites and toxins, thereby affecting central and peripheral inflammatory processes in $\mathrm{AD}$.

\section{THERAPEUTIC STRATEGIES TARGETING THE GUT MICROBIOTA AND METABOLITES IN AD}

\section{Pro-, Pre- and Antibiotics \\ Probiotics}

Probiotics consist of living microbes and can introduce beneficial microbial components that are missing in the host (126). In APP/ PS1 mice, treatment with probiotics containing Bifidobacterium longum and Lactobacillus acidophilus in combination with exercise was able to inhibit the progression of cognitive impairment and $A \beta$ deposition (50). These species, among other strains within Bifidobacterium and Lactobacillus, provide cross-feeding to butyrate-producers (127). Before treatment, APP/PS1 mice showed higher abundance of several Bacteroides species and a reduction of butyrate-producing strains compared to WT mice. Probiotic treatment in combination with exercise decreased the gram-negative species B. fragilis and Bacteroides thetaiotaomicron, of which the latter was related to poorer spatial memory, while both of these species were increased by probiotics alone. Butyrateproducing genera like Eubacterium and Roseburia were enhanced by probiotic treatment in combination with exercise, but decreased by probiotic treatment alone. Exercise without probiotic supplementation was also able to reverse the alterations in butyrate producing species and in $B$. fragilis that were seen in APP/PS1 mice, but did not decrease B. thetaiotaomicron. Accordingly, spatial memory was improved by exercise and probiotic treatment combined, but not considerably altered by exercise or probiotics separately. A $\beta$ pathology was decreased by probiotics and exercise separately, and by combined treatment (50).

$\mathrm{AD}$ patients who received probiotics containing species of Bifidobacterium bifidum, Lactobacillus fermentum, Lactobacillus casei and Lactobacillus acidophilus, which provide cross-feeding to butyrate-producing bacteria, showed improvement on the Mini Mental State Exam (MMSE) compared to untreated patients (128). Probiotic treatment in AD patients also resulted in favorable changes in insulin metabolism and in malondialdehyde (MDA) and high sensitivity C-reactive protein (hs-CRP), which are markers for oxidative stress and inflammation respectively, but was ineffective on other biomarkers of oxidative stress and inflammation such as total antioxidant capacity (TAC), nitric oxide (NO) and glutathione (GSH). Of note, the effect of probiotic treatment on microbiota composition was not investigated and as such, no firm 
conclusions can be drawn whether results were mediated by probiotic-induced changes in microbiota composition (128).

\section{Prebiotics}

Prebiotics are defined as substrates selectively used by host microorganisms to produce health benefits. The main source of prebiotics are plant-derived carbohydrate compounds called oligosaccharides (129). Prebiotics are non-digestible by the host, selectively fermented by intestinal microorganisms and selectively targeting and stimulating growth and activity of beneficial bacteria, especially Bifidobacterium and, to a lesser extent, Lactobacillus (129). Rats that received a hippocampal injection of $A \beta 42$ and were orally treated with oligosaccharides from Morinda officinalis (OMO) afterwards show improved learning and memory in a dose dependent way, ameliorated neuronal loss, decreased $\mathrm{A} \beta 42$ expression and reduced oxidative stress. In these rats, OMO treatment decreased both pro-inflammatory cytokines and antiinflammatory IL-10 to a level similar to WT. Moreover, OMO treatment restored the abundance of both Bacteroidetes and Firmicutes to WT levels (130). In APP/PS1 mice, OMO treatment induced an increase in Firmicutes, particularly in the butyrateproducing family Lachnospiraceae, while a decrease was seen in Bacteroidetes and the genus Bacteroides. Interestingly, an increase in Firmicutes and Lachnospiraceae and a reduction in Bacteroidetes were also observed in APP/PS1 mice compared to WT. Similar to rats, $\mathrm{OMO}$ treatment improved learning and memory in a dose dependent way (49). Together, these studies show that OMO treatment can affect different aspects of $\mathrm{AD}$ pathology like neuronal loss, cognitive deficits, inflammation, oxidative stress and A 342 expression, and that OMO might exert these effects via modulating microbiota composition $(49,130)$.

\section{Antibiotics}

Antibiotics are commonly used to limit bacterial colonization of the body, without targeting specific taxa, and can lead to significant alterations in gut microbiota composition (131).

Studies have reported that antibiotic treatment can ameliorate neuroinflammation and other aspects of $\mathrm{AD}$ pathology, including $\mathrm{A} \beta$ and tau accumulation and oxidative stress (132). Antibiotic treatment in $\mathrm{AD}$ mouse models affected $\mathrm{AD}$ pathology in a sex-specific manner. Male APP/PS1 mice showed a significant decrease in A $\beta$ plaque compared to untreated animals after antibiotic treatment, a result that was not observed in females (133). In males, antibiotic treatment reduced microglial and astroglial reactivity around $A \beta$ plaques (133), while an activated microglial phenotype was observed independent of antibiotic treatment in female mice (134). Additionally, antibiotic treated males had decreased expression of pro-inflammatory cytokines like IL-1 $\beta$ and IL-17A, while these cytokines were increased in antibiotic treated females. Furthermore, the antibiotic treatment induced sex-specific changes in microbiota composition. Also, antibiotics inhibited pathways related to LPS synthesis, but this effect was stronger in males than in females (134). These results were at least partially microbiome-dependent since microbiota transplantation from untreated male APP/PS1 mice to antibiotic treated mice resulted in partial restoration of $A \beta$ deposition and microglial morphology (134).
So far, contradicting results have been reported between clinical trials. One study demonstrated that high doses (50-100 $\mathrm{mg}$ ) of the antibiotic D-cycloserine, administered over a period of 4 weeks, improved cognition in AD patients (135), while an earlier study that treated patients with lower doses (15 mg) for the same period showed no effects (136). In 2004, a combined treatment of doxycycline and rifampicin for a period of 3 months resulted in significantly less cognitive decline over the 6-month period after the start of the treatment in patients with probable $\mathrm{AD}$ and mild to moderate dementia, compared to the placebo treated group (137). In contrast, a later study in 2013 found no beneficial effects of a 12-month treatment with either doxycycline or rifampin, or combined treatment, on cognition in $\mathrm{AD}$ patients (138).

The reason for these discrepancies regarding the effects of antibiotics might be the multifactorial nature of $\mathrm{AD}$, or other systemic effects of the antibiotic besides changing microbiota composition. The outcome of clinical trials can also be affected by participants being infected with $H$. pylori, which is quite common in older patients. As such, cognitive improvement that is observed in infected patients might be a result of elimination of the $H$. pylori infection by antibiotics $(131,139)$. Also, while some studies examined the effect of antibiotic treatment directly after the treatment period $(135,136,138)$, one performed cognitive assessment months after the treatment had stopped (137). In both cases, the treatment was reported to improve cognitive decline $(135,137)$, suggesting cognition was improved by a significant reduction in microbial diversity or in specific taxa right after antibiotic treatment, but also by a changed composition after repopulation. Still, other studies showed no effect of antibiotics directly after the treatment $(136,138)$.

In summary, research suggests that the use of antibiotics can at least interfere with $\mathrm{AD}$ pathology and associated neuroinflammation. However, microbiome-independent effects of antibiotics in GF mice, which lack microbiota, have been described that included changed host metabolites and inhibited respiratory activity in immune cells, consequently impairing immune phagocytic activity (140). In addition, antibiotic treatment has shown to induce FoxP3 ${ }^{+}$Treg cell in GF animals (141). Hence, it can be debated if the reported neuro-protective effects of antibiotic treatment were mediated via changes in the gut microbiome or via other pathways. Future research should elucidate if the effects of antibiotic treatment are mediated via changes in microbiota composition, via direct effects on immune cells or via other pathways in the host.

\section{Polysaccharide A (PSA) Treatment}

No research has yet been performed on the possible beneficial effects of PSA on cognition or neuroinflammation in AD. However, PSA treatment reduced disease severity of mice with experimental autoimmune encephalomyelitis (EAE), which is often used to model the neuro-inflammatory disease multiple sclerosis (MS) (142). In addition, treatment of EAE mice with PSA reduced neuroinflammation by reducing pro-inflammatory cytokines in a TLR2 dependent manner (143) and through inhibition of Th1 and Th17 responses (142). If PSA administration can interfere with pathological processes in $\mathrm{AD}$ remains to be investigated. However, 
since the immunological response to PSA exposure could be dependent on the inflammatory context (81), other therapeutic strategies targeting the gut microbiota and metabolites in $\mathrm{AD}$ might be more promising for future research.

\section{Butyrate Treatment}

Treatment with butyrate in GF male mice decreased BBB permeability and increased expression of the tight junction protein occludin. The same effect on BBB permeability was observed after monocolonization of GF mice with the butyrate producing bacteria Clostridium tyrobutyricum (144). Besides, pretreatment of adult and aged mice with a single injection of butyrate decreased LPS-induced IL-1 $\beta$ expression in microglia. Notably, the observed effect was stronger in aged mice. Pretreatment with butyrate also decreased LPS-induced IL-1 $\beta$ expression in the hippocampus of aged mice (145).

In APP/PS1 mice studies at advanced disease stage, treatment with butyrate resulted in improved memory function via HDAC inhibition, but did not affect A $\beta$ pathology (146). Accordingly, treatment of aged Tg2576 mice with butyrate also improved cognition without affecting $A \beta$ pathology, but decreased tau pathology and improved synaptic plasticity (147). In 5XFAD mice, butyrate both decreased $A \beta$ deposition and improved cognition. Here, the effect of the treatment in an early disease stage was examined (148), suggesting that the effect of butyrate on $\mathrm{A} \beta$ deposition might be dependent on disease stage. Additionally, treatment of APP/PS1 mice with Clostridium butyricum increased fecal butyrate concentrations and ameliorated cognitive deficits and neurodegeneration, suppressed microglia activation and decreased levels of the pro-inflammatory cytokines Il-1 $\beta$ and TNF- $\alpha$. Besides, Clostridium butyricum reversed microbiota alterations that were observed in APP/PS1 mice (149). No studies have yet been performed on the effect of butyrate treatment on $\mathrm{AD}$ pathology in humans. Altogether, usage of butyrate both reversed microbiota alterations and was able to interfere with neuroinflammation, $\mathrm{BBB}$ permeability, cognitive decline and, in early stage, pathological hallmarks like $A \beta$ and tau in mouse models of AD.

\section{Additional Dietary Interventions Calorie Restriction}

The effects of dietary restriction, which can be either caloric reduction or intermittent fasting, on neuroinflammation are well summarized by Bok et al., which states that dietary restriction can reduce neuroinflammation via several mechanisms, including inhibition of the NF- $\kappa \mathrm{B}$ pathway, or attenuation of aged-associated pro-inflammatory activation of astrocytes and microglia (150). Calorie restriction (CR) rescued most microbiota alterations that occur with increasing age in Tg2576 $\mathrm{AD}$ mice, and downregulated genes associated with intestinal inflammation (54) and reduced $A \beta$ pathology (151). In contrast, CR also upregulated transcription factor Roryt, which promotes a Th17 response (54). Interestingly, the CR diet as described by Cox et al. restricts only in carbohydrates (54), which are a source for butyrate production (16). However, if CR lowered butyrate levels was not investigated.

\section{High Fiber Diet}

Dietary intervention with fibers has shown to affect gut microbiota composition and levels of SCFAs. Supplementation of diets of healthy young adults for 2 weeks with three fermentable fibers resulted in an increase in SCFAs, including butyrate. As a response to resistant starch from potatoes, some participants showed an increase in Ruminococcus bromii or Clostridium chartatabidum, and this was associated with higher butyrate concentrations, especially in the presence of $E$. rectale (152). High fiber diet decreased the expression of inflammatory cytokines like IL-1 $\beta$, TNF and IL-6 in microglia from adult and aged mice (145). Expression of these cytokines was negatively correlated to cecal levels of butyrate (145). Hence, a high fiber diet is able to modulate neuro-immunological processes probably via an increase in butyrate levels.

\section{Mediterranean Diet}

Adherence to a Mediterranean diet (MD) is associated with a lower risk for developing $\mathrm{AD}$ and delay in cognitive decline (153). This diet is characterized by high intake of fruits, vegetables, legumes, nuts, cereals, olive oil and fish, moderate intake of dairy, low intake of meat, and small quantities of wine (154). Through its antioxidant properties, MD is beneficial in combating oxidative stress in AD (153). Besides, dietary components like beneficial unsaturated fatty acids provide anti-inflammatory actions (155), and MD was found to be associated with lower levels of inflammatory markers like Creactive protein (CRP) and IL-6 (156). MD also affects the gut microbiota and its metabolites, and has been linked to increased production of SCFAs (157). A cohort study with 153 Italian individuals following different diets showed that adherence to the MD correlates to higher fecal levels of acetate, propionate and butyrate (158). Accordingly, MD has been associated with increased abundance of butyrate-producing strains like $F$. prausnitzii $(157,159)$ and E. rectale $(160)$ and the butyrateproducing genus Roseburia (161) and to reduced levels of circulating LPS (162).

\section{Fecal Microbiota Transplantation}

Fecal microbiota transplantation (FMT) is the infusion of feces from a healthy donor into the gut of a recipient with the aim of targeting microbiota composition and is a promising strategy for combating disease associated with microbiota imbalance (163168). FMT treatment is generally considered safe, especially after extensive donor screening and testing $(169,170)$ but remains technically challenging (donor selection and preparation of the fecal transplant). In the future, specific supplementation of a (combination of) beneficial strains could be more feasible on a larger scale (169).

In APP/PS1 mice, FMT from WT mice for a period of 4 weeks improved spatial memory and reduced $A \beta$ accumulation and tau phosphorylation. Besides, FMT increased expression of proteins involved in synaptic plasticity, PSD-95 and synapsin I, and decreased inflammatory protein Cox-2 in the cortex and hippocampus. In addition, FMT reduced CD11b expression, which is a marker for microglia and other myeloid cells (171, 172 ), that was increased in APP/PS1 compared to WT mice. 
Alterations in microbiota composition in APP/PS1 mice compared to WT, including a reduction in Bacteroidetes, were reversed by FMT. Moreover, FMT increased levels of butyrate (171). Another study shows that FMT from WT to ADLPAPT mice, a relatively newly developed $\mathrm{AD}$ mouse model, resulted in decreased formation of $\mathrm{A} \beta$ plaques and neurofibrillary tangles, reduced glial activity and improved cognition (173). So far, no studies have investigated the effect of FMT in AD patients. However, an effect of FMT on the brain was demonstrated in obese patients, where FMT increased dopamine transporter binding which was associated with an concomitant increase in Bacteroides uniformis (174).

Overall, it seems that FMT treatment in AD mouse models has the potential to reverse microbiota alterations, improve cognition and synaptic plasticity, decrease $A \beta$ and tau pathology and to reduce neuroinflammation $(171,173)$.

\section{DISCUSSION}

This review shows different alterations in microbiota composition in $\mathrm{AD}$. Compositional differences across $\mathrm{AD}$ mouse studies were contradicting, as gram-negative and butyrate-producing bacteria were both increased and decreased in abundance. Limited but available human data revealed a higher abundance of gramnegative species within Bacteroidetes while species within Firmicutes that produce the metabolite butyrate were decreased. As such, it seems that results observed in mouse models of $\mathrm{AD}$ are not completely translatable towards humans.

Differences in microbiota composition between $\mathrm{AD}$ patients and $\mathrm{AD}$ animal models might be explained by differences in anatomy $(175,176)$ or in the used research techniques; while human studies use stool samples, cecal contents are mostly used in mouse studies (176). Another possible explanation is the absence of correction for confounding factors such as age, sex, diet, comorbidities, use of medication and inclusion of small sample sizes in human studies. Moreover, discrepancy in the findings might also be a result of the male/female ratio in these studies as sex-differences in gut microbiota composition have been acknowledged in humans (177) and in mice (56, 57, 178, 179). In $\mathrm{AD}$ mouse models, disease manifestation differs between males and females. Rapid and more severe AD pathology has been reported in females compared to males, including increased A $\beta$ pathology $(180,181)$, tau phosphorylation (180) and neuroinflammation $(181,182)$ and cognitive deficits (183). Possibly, different disease manifestation between sexes in $\mathrm{AD}$ transgenic mouse models influences microbiota composition or vice versa. In humans, variation in $\mathrm{AD}$ disease manifestation has also been observed between men and women, and includes differences in cognitive symptoms and brain atrophy (184). Further research should shed more light on the possible relationship between sex-differences in disease manifestation and variations in microbiota composition in $\mathrm{AD}$.

Lastly, all but one mouse study used a transgenic AD mousemodel with mutations associated with familial AD leading to early and excessive $\mathrm{A} \beta$ pathology. As such, detected shifts in microbiota composition are probably more characteristic to $A \beta$ pathology of familial $\mathrm{AD}$ and can differ when other $\mathrm{AD}$-associated pathologies are investigated. Also, mice and humans standardly show differences in microbiota composition, and raising the animals under specific pathogen free (SPF) conditions can reduce microbial diversity. Differences between mice and humans in microbiome research might be closed by using mice with humanized microbiota (185). However, generation of such animals is difficult, as successful transplantation of human gut microbiota into mice is under influence of anatomical and physiological factors, diet and environmental stimuli (186).

Innate immune activation in $\mathrm{AD}$ might differently affect pathogenesis dependent on disease stage. An activated microglial response could limit $\mathrm{A} \beta$ pathology in early or middle stages of $\mathrm{AD}$ (187-189), while it exacerbates tau pathology and neuronal loss in late stages $(189,190)$. Since the effects of immune activation on $\mathrm{AD}$ pathogenesis seem to be dependent on disease stage, the relation between the gut microbiome and $\mathrm{AD}$ could be as well. Hypothesizing, inflammatory effects of the gut microbiota might inhibit aspects of $\mathrm{AD}$ pathology in early disease stages, while they exacerbate pathology in late stages. The variation in microbiota composition in $\mathrm{AD}$ observed between different studies in humans (58-60) and animal models (44-55) might also be dependent on disease stage. Hence, it would be interesting to investigate functional changes in microbiota composition over the course of disease progression in humans together with shifts in immune status. Accordingly, animal studies show microbiota alterations in $\mathrm{AD}$ mouse models over time $(48,53,54)$, suggesting that microbial changes correspond with disease progression.

Another possible way in which gut microbiota can induce immune activation is via their release of bacterial amyloids. Bacteria produce amyloids as part of their biofilm, a selfproduced extracellular matrix which protects the population from different environmental and host insults (191). Although bacterialderived amyloids differ in structure from CNS amyloid, it has been suggested that due to existing similarities in their tertiary structure $(192,193)$, bacterial amyloids may prime the immune system and induce misfolding of other host proteins through molecular mimicry (191, 194-197). For example, bacterial amyloid curli is recognized by the TLR2/TLR1 complex that also recognizes human A $\beta$. Apart from Escherichia coli and Salmonella enterica serovar Typhimurium, most of these observations are made in vitro (191). Hence, future research should reveal in vivo interactions between bacterial amyloid, the immune system and $\mathrm{AD}$ pathology.

Treatment strategies that target the microbiota and their metabolites, including pro-, pre- and antibiotics, butyrate treatment, and dietary interventions, have shown potential to modulate neuroinflammation and/or improve other aspects of AD pathology (Figure 5 and Supplementary Table 4). Prebiotics and dietary interventions such as a high fiber might be able to restore the functional core of the microbiome by providing necessary dietary compounds for beneficial microbial metabolism. Less is known about butyrate-treatment or FMT as a therapeutic option for $\mathrm{AD}$. However, both treatments were able to restore microbiota imbalance, enhance cognition and synaptic plasticity, decrease $\mathrm{AD}$ pathology and to reduce neuroinflammation in mouse 


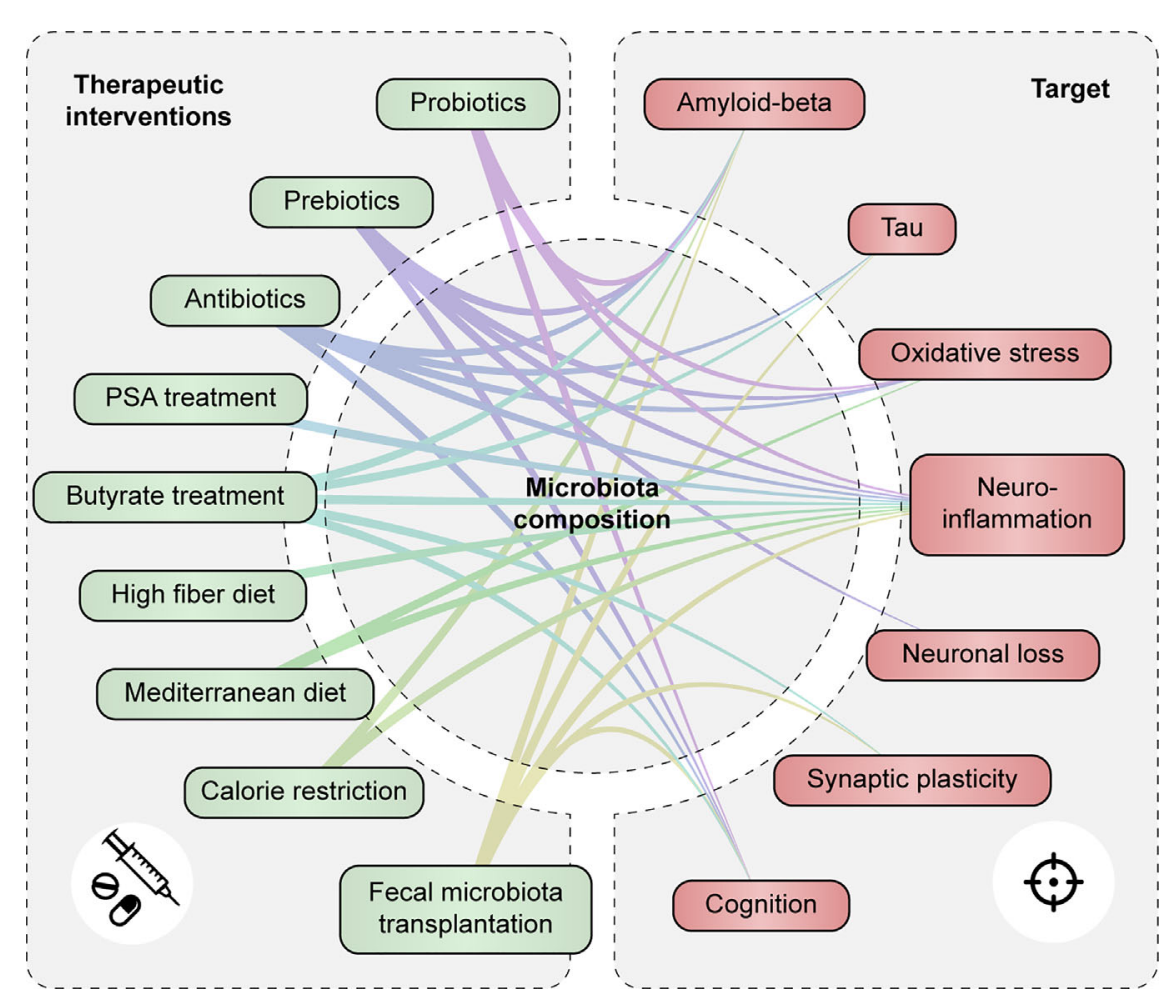

FIGURE 5 | Therapeutic strategies targeting the gut microbiota and metabolites modulate AD-associated pathology. Associations are shown between therapeutic interventions that modulate gut microbiota composition and/or function and AD-associated pathologies such as tau and A $\beta$ accumulation, oxidative stress and neuroinflammation, neuronal loss, synaptic plasticity and cognitive function.

models of $\mathrm{AD}$. As such, these therapeutic options could be promising to follow up in future studies.

In conclusion, gut microbiota composition shows many changes in $\mathrm{AD}$ patients and animal models, despite some inconsistencies in compositional differences between studies. It is clear however, that species of bacteria affect central and peripheral immune networks and have the ability to modulate ongoing neuro-immunological responses. Thus, restoring misbalanced microbiota in $\mathrm{AD}$ may present a future measure to increase immune fitness and alleviate $\mathrm{AD}$ pathology.

Still, recovering microbial balance with no general consensus on what characterizes the $\mathrm{AD}$-associated microbiome is doomed to face long odds. To overcome inconsistencies between studies in this field, future research should move towards studying the functionality and dynamics of the human core microbiome in $\mathrm{AD}$ rather than static abundance of microbial taxa, for example, by studying levels of immunomodulating metabolites, like PSA or butyrate, in relation to AD. Also, a better understanding is needed of how such dynamic alterations affect immune pathways and how these pathways can be therapeutically targeted. A good starting point would be the use of shotgun sequencing $(38,198,199)$ accompanied by immune profiling at different time-points of disease. Larger sample sizes in clinically well characterized cohorts could enable assessment of confounding/mediating effects of sex and other host factors such as diet in the relation between microbiota function, immune status and AD pathology. Finally, future studies should address how the microbiota-associated changes relate to $\mathrm{AD}$ biomarkers and disease severity, such as cerebral spinal fluid (CSF) or PET biomarkers for $\mathrm{A} \beta$ and tau, MRI characteristics or psychological assessment of cognitive functioning.

\section{AUTHOR CONTRIBUTIONS}

LO and SR wrote the manuscript. AK designed the figures. BV, AG, and MM provided valuable scientific input and revised the manuscript. LO, WF, and HV conceived the study and were involved in the overall supervision and editing of the manuscript. All authors contributed to the article and approved the submitted version.

\section{FUNDING}

This work was financed by Horizon 2020 \#686009 to HV.

\section{SUPPLEMENTARY MATERIAL}

The Supplementary Material for this article can be found online at: https://www.frontiersin.org/articles/10.3389/fimmu.2021. 683068/full\#supplementary-material 


\section{REFERENCES}

1. Sochocka M, Donskow-Lysoniewska K, Diniz BS, Kurpas D, Brzozowska E, Leszek J. The Gut Microbiome Alterations and Inflammation-Driven Pathogenesis of Alzheimer's Disease-a Critical Review. Mol Neurobiol (2019) 56(3):1841-51. doi: 10.1007/s12035-018-1188-4

2. Sun M, Ma K, Wen J, Wang G, Zhang C, Li Q, et al. A Review of the BrainGut-Microbiome Axis and the Potential Role of Microbiota in Alzheimer's Disease. J Alzheimers Dis (2020) 73(3):849-65. doi: 10.3233/JAD-190872

3. Long JM, Holtzman DM. Alzheimer Disease: An Update on Pathobiology and Treatment Strategies. Cell (2019) 179(2):312-39. doi: 10.1016/ j.cell.2019.09.001

4. Cao W, Zheng H. Peripheral Immune System in Aging and Alzheimer's Disease. Mol Neurodegener (2018) 13(1):51. doi: 10.1186/s13024-0180284-2

5. Le Page A, Dupuis G, Frost EH, Larbi A, Pawelec G, Witkowski JM, et al. Role of the Peripheral Innate Immune System in the Development of Alzheimer's Disease. Exp Gerontol (2018) 107:59-66. doi: 10.1016/ j.exger.2017.12.019

6. Rooks MG, Garrett WS. Gut Microbiota, Metabolites and Host Immunity. Nat Rev Immunol (2016) 16(6):341-52. doi: 10.1038/nri.2016.42

7. Belkaid Y, Hand TW. Role of the Microbiota in Immunity and Inflammation. Cell (2014) 157(1):121-41. doi: 10.1016/j.cell.2014.03.011

8. Parker A, Fonseca S, Carding SR. Gut Microbes and Metabolites as Modulators of Blood-Brain Barrier Integrity and Brain Health. Gut Microbes (2020) 11(2):135-57. doi: 10.1080/19490976.2019.1638722

9. Erny D, Hrabe de Angelis AL, Jaitin D, Wieghofer P, Staszewski O, David E, et al. Host Microbiota Constantly Control Maturation and Function of Microglia in the CNS. Nat Neurosci (2015) 18(7):965-77. doi: 10.1038/ nn. 4030

10. Thursby E, Juge N. Introduction to the Human Gut Microbiota. Biochem J (2017) 474(11):1823-36. doi: 10.1042/BCJ20160510

11. Turpin W, Espin-Garcia O, Xu W, Silverberg MS, Kevans D, Smith MI, et al. Association of Host Genome With Intestinal Microbial Composition in a Large Healthy Cohort. Nat Genet (2016) 48(11):1413-7. doi: 10.1038/ ng. 3693

12. Tap J, Mondot S, Levenez F, Pelletier E, Caron C, Furet JP, et al. Towards the Human Intestinal Microbiota Phylogenetic Core. Environ Microbiol (2009) 11(10):2574-84. doi: 10.1111/j.1462-2920.2009.01982.x

13. Hugon P, Dufour JC, Colson P, Fournier PE, Sallah K, Raoult D. A Comprehensive Repertoire of Prokaryotic Species Identified in Human Beings. Lancet Infect Dis (2015) 15(10):1211-9. doi: 10.1016/S1473-3099 (15)00293-5

14. Li J, Jia H, Cai X, Zhong H, Feng Q, Sunagawa S, et al. An Integrated Catalog of Reference Genes in the Human Gut Microbiome. Nat Biotechnol (2014) 32(8):834-41. doi: 10.1038/nbt.2942

15. Li Z, Zhu H, Zhang L, Qin C. The Intestinal Microbiome and Alzheimer's Disease: A Review. Anim Model Exp Med (2018) 1(3):180-8. doi: 10.1002/ ame2.12033

16. Louis P, Flint HJ. Diversity, Metabolism and Microbial Ecology of ButyrateProducing Bacteria From the Human Large Intestine. FEMS Microbiol Lett (2009) 294(1):1-8. doi: 10.1111/j.1574-6968.2009.01514.x

17. Barka EA, Vatsa P, Sanchez L, Gaveau-Vaillant N, Jacquard C, MeierKolthoff JP, et al. Taxonomy, Physiology, and Natural Products of Actinobacteria. Microbiol Mol Biol Rev (2016) 80(1):1-43. doi: 10.1128/ MMBR.00019-15

18. Rizzatti G, Lopetuso LR, Gibiino G, Binda C, Gasbarrini A. Proteobacteria: A Common Factor in Human Diseases. BioMed Res Int (2017) 2017:9351507. doi: $10.1155 / 2017 / 9351507$

19. Schlesner H, Jenkins C, Staley J. The Phylum Verrucomicrobia: A Phylogenetically Heterogeneous Bacterial Group. In: M Dworkin, editor. The Prokaryotes. New York: Spring (2006). p. 7.

20. Claesson MJ, Cusack S, O'Sullivan O, Greene-Diniz R, de Weerd H, Flannery E, et al. Composition, Variability, and Temporal Stability of the Intestinal Microbiota of the Elderly. Proc Natl Acad Sci USA (2011) 108 Suppl 1:4586-91. doi: 10.1073/pnas.1000097107

21. Odamaki T, Kato K, Sugahara H, Hashikura N, Takahashi S, Xiao JZ, et al. Age-Related Changes in Gut Microbiota Composition From Newborn to
Centenarian: A Cross-Sectional Study. BMC Microbiol (2016) 16:90. doi: 10.1186/s12866-016-0708-5

22. Malard F, Dore J, Gaugler B, Mohty M. Introduction to Host Microbiome Symbiosis in Health and Disease. Mucosal Immunol (2021) 14(3):547-54. doi: 10.1038/s41385-020-00365-4

23. Stadlbauer V, Engertsberger L, Komarova I, Feldbacher N, Leber B, Pichler G, et al. Dysbiosis, Gut Barrier Dysfunction and Inflammation in Dementia: A Pilot Study. BMC Geriatrics (2020) 20(1):248. doi: 10.1186/s12877-02001644-2

24. d'Hennezel E, Abubucker S, Murphy LO, Cullen TW. Total Lipopolysaccharide From the Human Gut Microbiome Silences Toll-Like Receptor Signaling. mSystems (2017) 2(6). doi: 10.1128/mSystems.00046-17

25. Lu YC, Yeh WC, Ohashi PS. LPS/TLR4 Signal Transduction Pathway. Cytokine (2008) 42(2):145-51. doi: 10.1016/j.cyto.2008.01.006

26. Round JL, Lee SM, Li J, Tran G, Jabri B, Chatila TA, et al. The Toll-like Receptor 2 Pathway Establishes Colonization by a Commensal of the Human Microbiota. Science (2011) 332(6032):974-7. doi: 10.1126/ science. 1206095

27. Round JL, Mazmanian SK. Inducible Foxp3+ Regulatory T-cell Development by a Commensal Bacterium of the Intestinal Microbiota. Proc Natl Acad Sci USA (2010) 107(27):12204-9. doi: 10.1073/ pnas.0909122107

28. Shen Y, Giardino Torchia ML, Lawson GW, Karp CL, Ashwell JD, Mazmanian SK. Outer Membrane Vesicles of a Human Commensal Mediate Immune Regulation and Disease Protection. Cell Host Microbe (2012) 12(4):509-20. doi: 10.1016/j.chom.2012.08.004

29. Liu H, Wang J, He T, Becker S, Zhang G, Li D, et al. Butyrate: A DoubleEdged Sword for Health? Adv Nutr (2018) 9(1):21-9. doi: 10.1093/advances/ nmx009

30. Singh N, Gurav A, Sivaprakasam S, Brady E, Padia R, Shi H, et al. Activation of Gpr109a, Receptor for Niacin and the Commensal Metabolite Butyrate, Suppresses Colonic Inflammation and Carcinogenesis. Immunity (2014) 40 (1):128-39. doi: 10.1016/j.immuni.2013.12.007

31. Chang PV, Hao L, Offermanns S, Medzhitov R. The Microbial Metabolite Butyrate Regulates Intestinal Macrophage Function Via Histone Deacetylase Inhibition. Proc Natl Acad Sci USA (2014) 111(6):2247-52. doi: 10.1073/ pnas. 1322269111

32. Redondo-Useros N, Nova E, Gonzalez-Zancada N, Diaz LE, GomezMartinez S, Marcos A. Microbiota and Lifestyle: A Special Focus on Diet. Nutrients (2020) 12(6):1776. doi: 10.3390/nu12061776

33. Claesson MJ, Jeffery IB, Conde S, Power SE, O'Connor EM, Cusack S, et al. Gut Microbiota Composition Correlates With Diet and Health in the Elderly. Nature (2012) 488(7410):178-84. doi: 10.1038/nature11319

34. Rothschild D, Weissbrod O, Barkan E, Kurilshikov A, Korem T, Zeevi D, et al. Environment Dominates Over Host Genetics in Shaping Human Gut Microbiota. Nature (2018) 555(7695):210-5. doi: 10.1038/ nature 25973

35. Dwiyanto J, Hussain MH, Reidpath D, Ong KS, Qasim A, Lee SWH, et al. Ethnicity Influences the Gut Microbiota of Individuals Sharing a Geographical Location: A Cross-Sectional Study From a Middle-Income Country. Sci Rep (2021) 11(1):2618. doi: 10.1038/s41598-021-82311-3

36. Gupta VK, Paul S, Dutta C. Geography, Ethnicity or Subsistence-Specific Variations in Human Microbiome Composition and Diversity. Front Microbiol (2017) 8:1162. doi: 10.3389/fmicb.2017.01162

37. Blum HE. The Human Microbiome. Adv Med Sci (2017) 62(2):414-20. doi: 10.1016/j.advms.2017.04.005

38. Qin J, Li R, Raes J, Arumugam M, Burgdorf KS, Manichanh C, et al. A Human Gut Microbial Gene Catalogue Established by Metagenomic Sequencing. Nature (2010) 464(7285):59-65. doi: 10.1038/nature08821

39. Huse SM, Ye Y, Zhou Y, Fodor AA. A Core Human Microbiome as Viewed Through 16S rRNA Sequence Clusters. PloS One (2012) 7(6):e34242. doi: 10.1371/journal.pone.0034242

40. Sekelja M, Berget I, Naes T, Rudi K. Unveiling an Abundant Core Microbiota in the Human Adult Colon by a Phylogroup-Independent Searching Approach. ISME J (2011) 5(3):519-31. doi: 10.1038/ ismej.2010.129

41. Lloyd-Price J, Abu-Ali G, Huttenhower C. The Healthy Human Microbiome. Genome Med (2016) 8(1):51. doi: 10.1186/s13073-016-0307-y 
42. DeJong EN, Surette MG, Bowdish DME. The Gut Microbiota and Unhealthy Aging: Disentangling Cause From Consequence. Cell Host Microbe (2020) 28(2):180-9. doi: 10.1016/j.chom.2020.07.013

43. Bosco N, Noti M. The Aging Gut Microbiome and its Impact on Host Immunity. Genes Immun (2021). doi: 10.1038/s41435-021-00126-8

44. Brandscheid C, Schuck F, Reinhardt S, Schafer KH, Pietrzik CU, Grimm M, et al. Altered Gut Microbiome Composition and Tryptic Activity of the 5xFAD Alzheimer's Mouse Model. J Alzheimers Dis (2017) 56(2):775-88. doi: 10.3233/JAD-160926

45. Harach T, Marungruang N, Duthilleul N, Cheatham V, Mc Coy KD, Frisoni G, et al. Reduction of Abeta Amyloid Pathology in APPPS1 Transgenic Mice in the Absence of Gut Microbiota. Sci Rep (2017) 7:41802. doi: 10.1038/ srep41802

46. Shen L, Liu L, Ji HF. Alzheimer's Disease Histological and Behavioral Manifestations in Transgenic Mice Correlate With Specific Gut Microbiome State. J Alzheimers Dis (2017) 56(1):385-90. doi: 10.3233/ JAD-160884

47. Zhang L, Wang Y, Xiayu X, Shi C, Chen W, Song N, et al. Altered Gut Microbiota in a Mouse Model of Alzheimer's Disease. J Alzheimers Dis (2017) 60(4):1241-57. doi: 10.3233/JAD-170020

48. Bauerl C, Collado MC, Diaz Cuevas A, Vina J, Perez Martinez G. Shifts in Gut Microbiota Composition in an APP/PSS1 Transgenic Mouse Model of Alzheimer's Disease During Lifespan. Lett Appl Microbiol (2018) 66(6):46471. doi: $10.1111 /$ lam.12882

49. Xin Y, Diling C, Jian Y, Ting L, Guoyan H, Hualun L, et al. Effects of Oligosaccharides From Morinda Officinalis on Gut Microbiota and Metabolome of APP/PS1 Transgenic Mice. Front Neurol (2018) 9:412. doi: 10.3389/fneur.2018.00412

50. Abraham D, Feher J, Scuderi GL, Szabo D, Dobolyi A, Cservenak M, et al. Exercise and Probiotics Attenuate the Development of Alzheimer's Disease in Transgenic Mice: Role of Microbiome. Exp Gerontol (2019) 115:122-31. doi: 10.1016/j.exger.2018.12.005

51. Sun BL, Li WW, Wang J, Xu YL, Sun HL, Tian DY, et al. Gut Microbiota Alteration and Its Time Course in a Tauopathy Mouse Model. J Alzheimers Dis (2019) 70(2):399-412. doi: 10.3233/JAD-181220

52. Wang S, Jiang W, Ouyang T, Shen XY, Wang F, Qu YH, et al. Jatrorrhizine Balances the Gut Microbiota and Reverses Learning and Memory Deficits in APP/PS1 Transgenic Mice. Sci Rep (2019) 9(1):19575. doi: 10.1038/s41598019-56149-9

53. Wang X, Sun G, Feng T, Zhang J, Huang X, Wang T, et al. Sodium Oligomannate Therapeutically Remodels Gut Microbiota and Suppresses Gut Bacterial Amino Acids-Shaped Neuroinflammation to Inhibit Alzheimer's Disease Progression. Cell Res (2019) 29(10):787-803. doi: 10.1038/s41422-019-0216-x

54. Cox LM, Schafer MJ, Sohn J, Vincentini J, Weiner HL, Ginsberg SD, et al. Calorie Restriction Slows Age-Related Microbiota Changes in an Alzheimer's Disease Model in Female Mice. Sci Rep (2019) 9(1):17904. doi: 10.1038/s41598-019-54187-x

55. Chen Y, Fang L, Chen S, Zhou H, Fan Y, Lin L, et al. Gut Microbiome Alterations Precede Cerebral Amyloidosis and Microglial Pathology in a Mouse Model of Alzheimer's Disease. BioMed Res Int (2020) 2020:8456596. doi: $10.1155 / 2020 / 8456596$

56. Org E, Mehrabian M, Parks BW, Shipkova P, Liu X, Drake TA, et al. Sex Differences and Hormonal Effects on Gut Microbiota Composition in Mice. Gut Microbes (2016) 7(4):313-22. doi: 10.1080/19490976.2016.1203502

57. Yurkovetskiy L, Burrows M, Khan AA, Graham L, Volchkov P, Becker L, et al. Gender Bias in Autoimmunity is Influenced by Microbiota. Immunity (2013) 39(2):400-12. doi: 10.1016/j.immuni.2013.08.013

58. Vogt NM, Kerby RL, Dill-McFarland KA, Harding SJ, Merluzzi AP, Johnson SC, et al. Gut Microbiome Alterations in Alzheimer's Disease. Sci Rep (2017) 7(1):13537. doi: 10.1038/s41598-017-13601-y

59. Zhuang ZQ, Shen LL, Li WW, Fu X, Zeng F, Gui L, et al. Gut Microbiota is Altered in Patients With Alzheimer's Disease. J Alzheimers Dis (2018) 63 (4):1337-46. doi: 10.3233/JAD-180176

60. Haran JP, Bhattarai SK, Foley SE, Dutta P, Ward DV, Bucci V, et al. Alzheimer's Disease Microbiome Is Associated With Dysregulation of the Anti-Inflammatory P-Glycoprotein Pathway. mBio (2019) 10(3). doi: 10.1128/mBio.00632-19
61. Cattaneo A, Cattane N, Galluzzi S, Provasi S, Lopizzo N, Festari C, et al. Association of Brain Amyloidosis With Pro-Inflammatory Gut Bacterial Taxa and Peripheral Inflammation Markers in Cognitively Impaired Elderly. Neurobiol Aging (2017) 49:60-8. doi: 10.1016/j.neurobiolaging.2016.08.019

62. Marizzoni M, Cattaneo A, Mirabelli P, Festari C, Lopizzo N, Nicolosi V, et al. Short-Chain Fatty Acids and Lipopolysaccharide as Mediators Between Gut Dysbiosis and Amyloid Pathology in Alzheimer's Disease. J Alzheimers Dis (2020) 78(2):683-97. doi: 10.3233/JAD-200306

63. Cani PD, Amar J, Iglesias MA, Poggi M, Knauf C, Bastelica D, et al. Metabolic Endotoxemia Initiates Obesity and Insulin Resistance. Diabetes (2007) 56(7):1761-72. doi: 10.2337/db06-1491

64. Tristao FSM, Rocha FA, Carlos D, Ketelut-Carneiro N, Souza COS, Milanezi CM, et al. Th17-Inducing Cytokines IL- 6 and IL-23 are Crucial for Granuloma Formation During Experimental Paracoccidioidomycosis. Front Immunol (2017) 8:949. doi: 10.3389/fimmu.2017.00949

65. Zhang J, Ke KF, Liu Z, Qiu YH, Peng YP. Th17 Cell-Mediated Neuroinflammation is Involved in Neurodegeneration of abeta1-42induced Alzheimer's Disease Model Rats. PloS One (2013) 8(10):e75786. doi: 10.1371/journal.pone. 0075786

66. Lukiw WJ. Bacteroides Fragilis Lipopolysaccharide and Inflammatory Signaling in Alzheimer's Disease. Front Microbiol (2016) 7:1544. doi: 10.3389/fmicb.2016.01544

67. Zhan X, Stamova B, Jin LW, DeCarli C, Phinney B, Sharp FR. GramNegative Bacterial Molecules Associate With Alzheimer Disease Pathology. Neurology (2016) 87(22):2324-32. doi: 10.1212/WNL.0000 000000003391

68. Mishra J, Zhang Q, Rosson JL, Moran J, Dopp JM, Neudeck BL. Lipopolysaccharide Increases Cell Surface P-glycoprotein That Exhibits Diminished Activity in Intestinal Epithelial Cells. Drug Metab Dispos (2008) 36(10):2145-9. doi: 10.1124/dmd.108.022632

69. Salkeni MA, Lynch JL, Otamis-Price T, Banks WA. Lipopolysaccharide Impairs Blood-Brain Barrier P-glycoprotein Function in Mice Through Prostaglandin- and Nitric Oxide-Independent Pathways. J Neuroimmune Pharmacol (2009) 4(2):276-82. doi: 10.1007/s11481-008-9138-y

70. van Assema DM, Lubberink M, Bauer M, van der Flier WM, Schuit RC, Windhorst $\mathrm{AD}$, et al. Blood-Brain Barrier P-glycoprotein Function in Alzheimer's Disease. Brain (2012) 135(Pt 1):181-9. doi: 10.1093/brain/ awr298

71. Cirrito JR, Deane R, Fagan AM, Spinner ML, Parsadanian M, Finn MB, et al. P-Glycoprotein Deficiency at the Blood-Brain Barrier Increases AmyloidBeta Deposition in an Alzheimer Disease Mouse Model. J Clin Invest (2005) 115(11):3285-90. doi: 10.1172/JCI25247

72. Wang W, Bodles-Brakhop AM, Barger SW. A Role for P-Glycoprotein in Clearance of Alzheimer Amyloid Beta -Peptide From the Brain. Curr Alzheimer Res (2016) 13(6):615-20. doi: 10.2174/1567205013666160314151012

73. Wijesuriya HC, Bullock JY, Faull RL, Hladky SB, Barrand MA. ABC Efflux Transporters in Brain Vasculature of Alzheimer's Subjects. Brain Res (2010) 1358:228-38. doi: 10.1016/j.brainres.2010.08.034

74. Chiu C, Miller MC, Monahan R, Osgood DP, Stopa EG, Silverberg GD. PGlycoprotein Expression and Amyloid Accumulation in Human Aging and Alzheimer's Disease: Preliminary Observations. Neurobiol Aging (2015) 36 (9):2475-82. doi: 10.1016/j.neurobiolaging.2015.05.020

75. Deo AK, Borson S, Link JM, Domino K, Eary JF, Ke B, et al. Activity of PGlycoprotein, a Beta-Amyloid Transporter at the Blood-Brain Barrier, Is Compromised in Patients With Mild Alzheimer Disease. J Nucl Med (2014) 55(7):1106-11. doi: 10.2967/jnumed.113.130161

76. Kawasaki A, Karasudani Y, Otsuka Y, Hasegawa M, Inohara N, Fujimoto Y, et al. Synthesis of Diaminopimelic Acid Containing Peptidoglycan Fragments and Tracheal Cytotoxin (TCT) and Investigation of Their Biological Functions. Chemistry (2008) 14(33):10318-30. doi: 10.1002/ chem. 200801121

77. Clarke TB, Davis KM, Lysenko ES, Zhou AY, Yu Y, Weiser JN. Recognition of Peptidoglycan From the Microbiota by Nod1 Enhances Systemic Innate Immunity. Nat Med (2010) 16(2):228-31. doi: 10.1038/nm.2087

78. Dasgupta S, Erturk-Hasdemir D, Ochoa-Reparaz J, Reinecker HC, Kasper DL. Plasmacytoid Dendritic Cells Mediate Anti-Inflammatory Responses to a Gut Commensal Molecule Via Both Innate and Adaptive Mechanisms. Cell Host Microbe (2014) 15(4):413-23. doi: 10.1016/j.chom.2014.03.006 
79. Mazmanian SK, Round JL, Kasper DL. A Microbial Symbiosis Factor Prevents Intestinal Inflammatory Disease. Nature (2008) 453(7195):620-5. doi: $10.1038 /$ nature 07008

80. Mazmanian SK, Liu CH, Tzianabos AO, Kasper DL. An Immunomodulatory Molecule of Symbiotic Bacteria Directs Maturation of the Host Immune System. Cell (2005) 122(1):107-18. doi: 10.1016/ j.cell.2005.05.007

81. Alvarez CA, Jones MB, Hambor J, Cobb BA. Characterization of Polysaccharide A Response Reveals Interferon Responsive Gene Signature and Immunomodulatory Marker Expression. Front Immunol (2020) 11:556813. doi: 10.3389/fimmu.2020.556813

82. Tan J, McKenzie C, Potamitis M, Thorburn AN, Mackay CR, Macia L. The Role of Short-Chain Fatty Acids in Health and Disease. Adv Immunol (2014) 121:91-119. doi: 10.1016/B978-0-12-800100-4.00003-9

83. Burger-van Paassen N, Vincent A, Puiman PJ, van der Sluis M, Bouma J, Boehm G, et al. The Regulation of Intestinal Mucin MUC2 Expression by Short-Chain Fatty Acids: Implications for Epithelial Protection. Biochem J (2009) 420(2):211-9. doi: 10.1042/BJ20082222

84. Suzuki T, Yoshida S, Hara H. Physiological Concentrations of Short-Chain Fatty Acids Immediately Suppress Colonic Epithelial Permeability. Br J Nutr (2008) 100(2):297-305. doi: 10.1017/S0007114508888733

85. Tazoe H, Otomo Y, Kaji I, Tanaka R, Karaki SI, Kuwahara A. Roles of ShortChain Fatty Acids Receptors, GPR41 and GPR43 on Colonic Functions. J Physiol Pharmacol (2008) 59 Suppl 2:251-62.

86. Haenen D, Zhang J, Souza da Silva C, Bosch G, van der Meer IM, van Arkel J, et al. A Diet High in Resistant Starch Modulates Microbiota Composition, SCFA Concentrations, and Gene Expression in Pig Intestine. J Nutr (2013) 143(3):274-83. doi: 10.3945/jn.112.169672

87. Atarashi K, Tanoue T, Oshima K, Suda W, Nagano Y, Nishikawa H, et al. Treg Induction by a Rationally Selected Mixture of Clostridia Strains From the Human Microbiota. Nature (2013) 500(7461):232-6. doi: 10.1038/ nature12331

88. Atarashi K, Tanoue T, Shima T, Imaoka A, Kuwahara T, Momose Y, et al. Induction of Colonic Regulatory T Cells by Indigenous Clostridium Species. Science (2011) 331(6015):337-41. doi: 10.1126/science.1198469

89. Quevrain E, Maubert MA, Michon C, Chain F, Marquant R, Tailhades J, et al. Identification of an Anti-Inflammatory Protein From Faecalibacterium Prausnitzii, a Commensal Bacterium Deficient in Crohn's Disease. Gut (2016) 65(3):415-25. doi: 10.1136/gutjnl-2014-307649

90. Takahashi K, Nishida A, Fujimoto T, Fujii M, Shioya M, Imaeda H, et al. Reduced Abundance of Butyrate-Producing Bacteria Species in the Fecal Microbial Community in Crohn's Disease. Digestion (2016) 93(1):59-65. doi: $10.1159 / 000441768$

91. Gutierrez N, Garrido D. Species Deletions From Microbiome Consortia Reveal Key Metabolic Interactions Between Gut Microbes. mSystems (2019) 4(4). doi: 10.1128/mSystems.00185-19

92. Chen D, Jin D, Huang S, Wu J, Xu M, Liu T, et al. Clostridium Butyricum, a Butyrate-Producing Probiotic, Inhibits Intestinal Tumor Development Through Modulating Wnt Signaling and Gut Microbiota. Cancer Lett (2020) 469:456-67. doi: 10.1016/j.canlet.2019.11.019

93. Kopecny J, Zorec M, Mrazek J, Kobayashi Y, Marinsek-Logar R. Butyrivibrio Hungatei Sp. Nov. and Pseudobutyrivibrio Xylanivorans Sp. Nov., ButyrateProducing Bacteria From the Rumen. Int J Syst Evol Microbiol (2003) 53(Pt 1):201-9. doi: 10.1099/ijs.0.02345-0

94. Moon CD, Pacheco DM, Kelly WJ, Leahy SC, Li D, Kopecny J, et al. Reclassification of Clostridium Proteoclasticum as Butyrivibrio Proteoclasticus Comb. Nov., a Butyrate-Producing Ruminal Bacterium. Int J Syst Evol Microbiol (2008) 58(Pt 9):2041-5. doi: 10.1099/ijs.0.65845-0

95. Duncan SH, Louis P, Flint HJ. Lactate-Utilizing Bacteria, Isolated From Human Feces, That Produce Butyrate as a Major Fermentation Product. Appl Environ Microbiol (2004) 70(10):5810-7. doi: 10.1128/ AEM.70.10.5810-5817.2004

96. Holmstrom K, Collins MD, Moller T, Falsen E, Lawson PA. Subdoligranulum Variabile Gen. Nov., Sp. Nov. From Human Feces. Anaerobe (2004) 10(3):197-203. doi: 10.1016/j.anaerobe.2004.01.004

97. Vital M, Karch A, Pieper DH. Colonic Butyrate-Producing Communities in Humans: An Overview Using Omics Data. mSystems (2017) 2(6). doi: 10.1128/mSystems.00130-17
98. La Rosa SL, Leth ML, Michalak L, Hansen ME, Pudlo NA, Glowacki R, et al. The Human Gut Firmicute Roseburia Intestinalis is a Primary Degrader of Dietary Beta-Mannans. Nat Commun (2019) 10(1):905. doi: 10.1038/ s41467-019-08812-y

99. Vinolo MA, Rodrigues HG, Hatanaka E, Sato FT, Sampaio SC, Curi R. Suppressive Effect of Short-Chain Fatty Acids on Production of Proinflammatory Mediators by Neutrophils. J Nutr Biochem (2011) 22 (9):849-55. doi: 10.1016/j.jnutbio.2010.07.009

100. Schwab M, Reynders V, Loitsch S, Steinhilber D, Stein J, Schroder O. Involvement of Different Nuclear Hormone Receptors in ButyrateMediated Inhibition of Inducible NF Kappa B Signalling. Mol Immunol (2007) 44(15):3625-32. doi: 10.1016/j.molimm.2007.04.010

101. Place RF, Noonan EJ, Giardina C. HDAC Inhibition Prevents NF-Kappa B Activation by Suppressing Proteasome Activity: Down-Regulation of Proteasome Subunit Expression Stabilizes I Kappa B Alpha. Biochem Pharmacol (2005) 70(3):394-406. doi: 10.1016/j.bcp.2005.04.030

102. Ang Z, Er JZ, Tan NS, Lu J, Liou YC, Grosse J, et al. Human and Mouse Monocytes Display Distinct Signalling and Cytokine Profiles Upon Stimulation With FFAR2/FFAR3 Short-Chain Fatty Acid Receptor Agonists. Sci Rep (2016) 6:34145. doi: 10.1038/srep34145

103. Zhang C, Chang J, Wu W, Deng Y, Zhou P, Jiang W, et al. Activation of GPR43 Suppresses TNF-alpha-induced Inflammatory Response in Human Fibroblast-Like Synoviocytes. Arch Biochem Biophys (2020) 684:108297. doi: 10.1016/j.abb.2020.108297

104. Zhang M, Zhou Q, Dorfman RG, Huang X, Fan T, Zhang H, et al. Butyrate Inhibits Inteleukin-17 and Generates Tregs to Ameliorate Colorectal Colitis in Rats. BMC Gastroenterol (2016) 16(1):84. doi: 10.1186/s12876016-0500-x

105. Gurav A, Sivaprakasam S, Bhutia YD, Boettger T, Singh N, Ganapathy V. Slc5a8, a Nat-coupled High-Affinity Transporter for Short-Chain Fatty Acids, is a Conditional Tumour Suppressor in Colon That Protects Against Colitis and Colon Cancer Under Low-Fibre Dietary Conditions. Biochem J (2015) 469(2):267-78. doi: 10.1042/BJ20150242

106. Smith PM, Howitt MR, Panikov N, Michaud M, Gallini CA, Bohlooly YM, et al. The Microbial Metabolites, Short-Chain Fatty Acids, Regulate Colonic Treg Cell Homeostasis. Science (2013) 341(6145):569-73. doi: 10.1126/ science. 1241165

107. Kespohl M, Vachharajani N, Luu M, Harb H, Pautz S, Wolff S, et al. The Microbial Metabolite Butyrate Induces Expression of Th1-Associated Factors in CD4(+) T Cells. Front Immunol (2017) 8:1036. doi: 10.3389/ fimmu.2017.01036

108. Hansen DV, Hanson JE, Sheng M. Microglia in Alzheimer's Disease. J Cell Biol (2018) 217(2):459-72. doi: 10.1083/jcb.201709069

109. Ulrich JD, Ulland TK, Colonna M, Holtzman DM. Elucidating the Role of TREM2 in Alzheimer's Disease. Neuron (2017) 94(2):237-48. doi: 10.1016/ j.neuron.2017.02.042

110. Gate D, Saligrama N, Leventhal O, Yang AC, Unger MS, Middeldorp J, et al. Clonally Expanded CD8 T Cells Patrol the Cerebrospinal Fluid in Alzheimer's Disease. Nature (2020) 577(7790):399-404. doi: 10.1038/ s41586-019-1895-7

111. Zenaro E, Pietronigro E, Della Bianca V, Piacentino G, Marongiu L, Budui S, et al. Neutrophils Promote Alzheimer's Disease-Like Pathology and Cognitive Decline Via LFA-1 Integrin. Nat Med (2015) 21(8):880-6. doi: 10.1038/nm.3913

112. Marsh SE, Abud EM, Lakatos A, Karimzadeh A, Yeung ST, Davtyan H, et al. The Adaptive Immune System Restrains Alzheimer's Disease Pathogenesis by Modulating Microglial Function. Proc Natl Acad Sci USA (2016) 113(9): E1316-25. doi: 10.1073/pnas.1525466113

113. Baruch K, Rosenzweig N, Kertser A, Deczkowska A, Sharif AM, Spinrad A, et al. Breaking Immune Tolerance by Targeting Foxp3(+) Regulatory T Cells Mitigates Alzheimer's Disease Pathology. Nat Commun (2015) 6:7967. doi: 10.1038/ncomms8967

114. Sweeney MD, Sagare AP, Zlokovic BV. Blood-Brain Barrier Breakdown in Alzheimer Disease and Other Neurodegenerative Disorders. Nat Rev Neurol (2018) 14(3):133-50. doi: 10.1038/nrneurol.2017.188

115. Fung TC, Olson CA, Hsiao EY. Interactions Between the Microbiota, Immune and Nervous Systems in Health and Disease. Nat Neurosci (2017) 20(2):145. doi: $10.1038 / \mathrm{nn} .4476$ 
116. Baganz NL, Blakely RD. A Dialogue Between the Immune System and Brain, Spoken in the Language of Serotonin. ACS Chem Neurosci (2013) 4(1):48-63. doi: $10.1021 / \mathrm{cn} 300186 \mathrm{~b}$

117. Barragan A, Weidner JM, Jin Z, Korpi ER, Birnir B. Gabaergic Signalling in the Immune System. Acta Physiol (Oxf) (2015) 213(4):819-27. doi: 10.1111/ apha. 12467

118. Weinstein LI, Revuelta A, Pando RH. Catecholamines and Acetylcholine are Key Regulators of the Interaction Between Microbes and the Immune System. Ann N Y Acad Sci (2015) 1351:39-51. doi: 10.1111/nyas.12792

119. Borovikova LV, Ivanova S, Zhang M, Yang H, Botchkina GI, Watkins LR, et al. Vagus Nerve Stimulation Attenuates the Systemic Inflammatory Response to Endotoxin. Nature (2000) 405(6785):458-62. doi: 10.1038/ 35013070

120. Houlden A, Goldrick M, Brough D, Vizi ES, Lenart N, Martinecz B, et al. Brain Injury Induces Specific Changes in the Caecal Microbiota of Mice Via Altered Autonomic Activity and Mucoprotein Production. Brain Behav Immun (2016) 57:10-20. doi: 10.1016/j.bbi.2016.04.003

121. Bellavance MA, Rivest S. The HPA - Immune Axis and the Immunomodulatory Actions of Glucocorticoids in the Brain. Front Immunol (2014) 5:136. doi: 10.3389/fimmu.2014.00136

122. Louveau A, Herz J, Alme MN, Salvador AF, Dong MQ, Viar KE, et al. CNS Lymphatic Drainage and Neuroinflammation are Regulated by Meningeal Lymphatic Vasculature. Nat Neurosci (2018) 21(10):1380-91. doi: 10.1038/ s41593-018-0227-9

123. Louveau A, Smirnov I, Keyes TJ, Eccles JD, Rouhani SJ, Peske JD, et al. Structural and Functional Features of Central Nervous System Lymphatic Vessels. Nature (2015) 523(7560):337-41. doi: 10.1038/nature14432

124. Aspelund A, Antila S, Proulx ST, Karlsen TV, Karaman S, Detmar M, et al. A Dural Lymphatic Vascular System That Drains Brain Interstitial Fluid and Macromolecules. J Exp Med (2015) 212(7):991-9. doi: 10.1084/jem.20142290

125. Banks WA. The Blood-Brain Barrier in Neuroimmunology: Tales of Separation and Assimilation. Brain Behav Immun (2015) 44:1-8. doi: 10.1016/j.bbi.2014.08.007

126. Preidis GA, Versalovic J. Targeting the Human Microbiome With Antibiotics, Probiotics, and Prebiotics: Gastroenterology Enters the Metagenomics Era. Gastroenterology (2009) 136(6):2015-31. doi: 10.1053/ j.gastro.2009.01.072

127. Moens F, Verce M, De Vuyst L. Lactate- and Acetate-Based Cross-Feeding Interactions Between Selected Strains of Lactobacilli, Bifidobacteria and Colon Bacteria in the Presence of Inulin-Type Fructans. Int J Food Microbiol (2017) 241:225-36. doi: 10.1016/j.ijfoodmicro.2016.10.019

128. Akbari E, Asemi Z, Daneshvar Kakhaki R, Bahmani F, Kouchaki E, Tamtaji OR, et al. Effect of Probiotic Supplementation on Cognitive Function and Metabolic Status in Alzheimer's Disease: A Randomized, Double-Blind and Controlled Trial. Front Aging Neurosci (2016) 8:256. doi: 10.3389/ fnagi.2016.00256

129. Gibson GR, Probert HM, Loo JV, Rastall RA, Roberfroid MB. Dietary Modulation of the Human Colonic Microbiota: Updating the Concept of Prebiotics. Nutr Res Rev (2004) 17(2):259-75. doi: 10.1079/NRR200479

130. Chen D, Yang X, Yang J, Lai G, Yong T, Tang X, et al. Prebiotic Effect of Fructooligosaccharides From Morinda Officinalis on Alzheimer's Disease in Rodent Models by Targeting the Microbiota-Gut-Brain Axis. Front Aging Neurosci (2017) 9:403. doi: 10.3389/fnagi.2017.00403

131. Angelucci F, Cechova K, Amlerova J, Hort J. Antibiotics, Gut Microbiota, and Alzheimer's Disease. J Neuroinflamm (2019) 16(1):108. doi: 10.1186/ s12974-019-1494-4

132. Yulug B, Hanoglu L, Ozansoy M, Isik D, Kilic U, Kilic E, et al. Therapeutic Role of Rifampicin in Alzheimer's Disease. Psychiatry Clin Neurosci (2018) 72(3):152-9. doi: 10.1111/pcn.12637

133. Minter MR, Zhang C, Leone V, Ringus DL, Zhang X, Oyler-Castrillo P, et al. Antibiotic-Induced Perturbations in Gut Microbial Diversity Influences Neuro-Inflammation and Amyloidosis in a Murine Model of Alzheimer's Disease. Sci Rep (2016) 6:30028. doi: 10.1038/srep30028

134. Dodiya HB, Kuntz T, Shaik SM, Baufeld C, Leibowitz J, Zhang X, et al. SexSpecific Effects of Microbiome Perturbations on Cerebral Abeta Amyloidosis and Microglia Phenotypes. J Exp Med (2019) 216(7):1542-60. doi: 10.1084/ jem. 20182386
135. Tsai GE, Falk WE, Gunther J, Coyle JT. Improved Cognition in Alzheimer's Disease With Short-Term D-cycloserine Treatment. Am J Psychiatry (1999) 156(3):467-9. doi: 10.1176/ajp.156.3.467

136. Tsai GE, Falk WE, Gunther J. A Preliminary Study of D-cycloserine Treatment in Alzheimer's Disease. J Neuropsychiatry Clin Neurosci (1998) 10(2):224-6. doi: 10.1176/jnp.10.2.224

137. Loeb MB, Molloy DW, Smieja M, Standish T, Goldsmith CH, Mahony J, et al. A Randomized, Controlled Trial of Doxycycline and Rifampin for Patients With Alzheimer's Disease. J Am Geriatr Soc (2004) 52(3):381-7. doi: 10.1111/j.1532-5415.2004.52109.x

138. Molloy DW, Standish TI, Zhou Q, Guyatt G, Group DS. A Multicenter, Blinded, Randomized, Factorial Controlled Trial of Doxycycline and Rifampin for Treatment of Alzheimer's Disease: The DARAD Trial. Int J Geriatr Psychiatry (2013) 28(5):463-70. doi: 10.1002/gps.3846

139. Pilotto A, Malfertheiner P. Review Article: An Approach to Helicobacter Pylori Infection in the Elderly. Aliment Pharmacol Ther (2002) 16(4):683-91. doi: 10.1046/j.1365-2036.2002.01226.x

140. Yang JH, Bhargava P, McCloskey D, Mao N, Palsson BO, Collins JJ. Antibiotic-Induced Changes to the Host Metabolic Environment Inhibit Drug Efficacy and Alter Immune Function. Cell Host Microbe (2017) 22 (6):757-65 e3. doi: 10.1016/j.chom.2017.10.020

141. Han D, Walsh MC, Kim KS, Hong SW, Lee J, Yi J, et al. MicrobiotaIndependent Ameliorative Effects of Antibiotics on Spontaneous Th2Associated Pathology of the Small Intestine. PloS One (2015) 10(2): e0118795. doi: 10.1371/journal.pone.0118795

142. Ochoa-Reparaz J, Mielcarz DW, Wang Y, Begum-Haque S, Dasgupta S, Kasper DL, et al. A Polysaccharide From the Human Commensal Bacteroides Fragilis Protects Against CNS Demyelinating Disease. Mucosal Immunol (2010) 3(5):487-95. doi: 10.1038/mi.2010.29

143. Wang Y, Telesford KM, Ochoa-Reparaz J, Haque-Begum S, Christy M, Kasper EJ, et al. An Intestinal Commensal Symbiosis Factor Controls Neuroinflammation Via TLR2-mediated CD39 Signalling. Nat Commun (2014) 5:4432. doi: 10.1038/ncomms5432

144. Braniste V, Al-Asmakh M, Kowal C, Anuar F, Abbaspour A, Toth M, et al. The Gut Microbiota Influences Blood-Brain Barrier Permeability in Mice. Sci Transl Med (2014) 6(263):263ra158. doi: 10.1126/scitranslmed.3009759

145. Matt SM, Allen JM, Lawson MA, Mailing LJ, Woods JA, Johnson RW. Butyrate and Dietary Soluble Fiber Improve Neuroinflammation Associated With Aging in Mice. Front Immunol (2018) 9:1832. doi: 10.3389/ fimmu. 2018.01832

146. Govindarajan N, Agis-Balboa RC, Walter J, Sananbenesi F, Fischer A. Sodium Butyrate Improves Memory Function in an Alzheimer's Disease Mouse Model When Administered at an Advanced Stage of Disease Progression. J Alzheimers Dis (2011) 26(1):187-97. doi: 10.3233/JAD2011-110080

147. Ricobaraza A, Cuadrado-Tejedor M, Perez-Mediavilla A, Frechilla D, Del Rio J, Garcia-Osta A. Phenylbutyrate Ameliorates Cognitive Deficit and Reduces Tau Pathology in an Alzheimer's Disease Mouse Model. Neuropsychopharmacology (2009) 34(7):1721-32. doi: 10.1038/npp.2008.229

148. Fernando W, Martins IJ, Morici M, Bharadwaj P, Rainey-Smith SR, Lim WLF, et al. Sodium Butyrate Reduces Brain Amyloid-Beta Levels and Improves Cognitive Memory Performance in an Alzheimer's Disease Transgenic Mouse Model at an Early Disease Stage. J Alzheimers Dis (2020) 74(1):91-9. doi: 10.3233/JAD-190120

149. Sun J, Xu J, Yang B, Chen K, Kong Y, Fang N, et al. Effect of Clostridium Butyricum Against Microglia-Mediated Neuroinflammation in Alzheimer's Disease Via Regulating Gut Microbiota and Metabolites Butyrate. Mol Nutr Food Res (2020) 64(2):e1900636. doi: 10.1002/mnfr.201900636

150. Bok E, Jo M, Lee S, Lee BR, Kim J, Kim HJ. Dietary Restriction and Neuroinflammation: A Potential Mechanistic Link. Int J Mol Sci (2019) 20 (3):464. doi: 10.3390/ijms20030464

151. Schafer MJ, Alldred MJ, Lee SH, Calhoun ME, Petkova E, Mathews PM, et al. Reduction of Beta-Amyloid and Gamma-Secretase by Calorie Restriction in Female Tg2576 Mice. Neurobiol Aging (2015) 36(3):1293-302. doi: 10.1016/ j.neurobiolaging.2014.10.043

152. Baxter NT, Schmidt AW, Venkataraman A, Kim KS, Waldron C, Schmidt TM. Dynamics of Human Gut Microbiota and Short-Chain Fatty Acids in 
Response to Dietary Interventions With Three Fermentable Fibers. mBio (2019) 10(1). doi: 10.1128/mBio.02566-18

153. Scarmeas N, Stern Y, Tang MX, Mayeux R, Luchsinger JA. Mediterranean Diet and Risk for Alzheimer's Disease. Ann Neurol (2006) 59(6):912-21. doi: 10.1002/ana.20854

154. Tapsell LC. Foods and Food Components in the Mediterranean Diet: Supporting Overall Effects. BMC Med (2014) 12:100. doi: 10.1186/17417015-12-100

155. Bifulco M. Mediterranean Diet: The Missing Link Between Gut Microbiota and Inflammatory Diseases. Eur J Clin Nutr (2015) 69(9):1078. doi: 10.1038/ ejcn.2015.81

156. Chrysohoou C, Panagiotakos DB, Pitsavos C, Das UN, Stefanadis C. Adherence to the Mediterranean Diet Attenuates Inflammation and Coagulation Process in Healthy Adults: The Attica Study. J Am Coll Cardiol (2004) 44(1):152-8. doi: 10.1016/j.jacc.2004.03.039

157. Wang DD, Nguyen LH, Li Y, Yan Y, Ma W, Rinott E, et al. The Gut Microbiome Modulates the Protective Association Between a Mediterranean Diet and Cardiometabolic Disease Risk. Nat Med (2021) 27(2):333-43. doi: 10.1038/s41591-020-01223-3

158. De Filippis F, Pellegrini N, Vannini L, Jeffery IB, La Storia A, Laghi L, et al. High-Level Adherence to a Mediterranean Diet Beneficially Impacts the Gut Microbiota and Associated Metabolome. Gut (2016) 65(11):1812-21. doi: 10.1136/gutjnl-2015-309957

159. Meslier V, Laiola M, Roager HM, De Filippis F, Roume H, Quinquis B, et al. Mediterranean Diet Intervention in Overweight and Obese Subjects Lowers Plasma Cholesterol and Causes Changes in the Gut Microbiome and Metabolome Independently of Energy Intake. Gut (2020) 69(7):1258-68. doi: 10.1136/gutjnl-2019-320438

160. Ghosh TS, Rampelli S, Jeffery IB, Santoro A, Neto M, Capri M, et al. Mediterranean Diet Intervention Alters the Gut Microbiome in Older People Reducing Frailty and Improving Health Status: The NU-AGE 1-Year Dietary Intervention Across Five European Countries. Gut (2020) 69(7):1218-28. doi: 10.1136/gutjnl-2019-319654

161. Nagpal R, Shively CA, Register TC, Craft S, Yadav H. Gut microbiomeMediterranean Diet Interactions in Improving Host Health. F1000Res (2019) 8:699. doi: 10.12688/f1000research.18992.1

162. Pastori D, Carnevale R, Nocella C, Novo M, Santulli M, Cammisotto V, et al. Gut-Derived Serum Lipopolysaccharide is Associated With Enhanced Risk of Major Adverse Cardiovascular Events in Atrial Fibrillation: Effect of Adherence to Mediterranean Diet. J Am Heart Assoc (2017) 6(6). doi: 10.1161/JAHA.117.005784

163. Paramsothy S, Kamm MA, Kaakoush NO, Walsh AJ, van den Bogaerde J, Samuel D, et al. Multidonor Intensive Faecal Microbiota Transplantation for Active Ulcerative Colitis: A Randomised Placebo-Controlled Trial. Lancet (2017) 389(10075):1218-28. doi: 10.1016/S0140-6736(17)30182-4

164. Rossen NG, Fuentes S, van der Spek MJ, Tijssen JG, Hartman JH, Duflou A, et al. Findings From a Randomized Controlled Trial of Fecal Transplantation for Patients With Ulcerative Colitis. Gastroenterology (2015) 149(1):110-8 e4. doi: 10.1053/j.gastro.2015.03.045

165. Moayyedi P, Surette MG, Kim PT, Libertucci J, Wolfe M, Onischi C, et al. Fecal Microbiota Transplantation Induces Remission in Patients With Active Ulcerative Colitis in a Randomized Controlled Trial. Gastroenterology (2015) 149(1):102-9.e6. doi: 10.1053/j.gastro.2015.04.001

166. Burrello C, Garavaglia F, Cribiu FM, Ercoli G, Lopez G, Troisi J, et al. Therapeutic Faecal Microbiota Transplantation Controls Intestinal Inflammation Through IL10 Secretion by Immune Cells. Nat Commun (2018) 9(1):5184. doi: 10.1038/s41467-018-07359-8

167. Tian Z, Liu J, Liao M, Li W, Zou J, Han X, et al. Beneficial Effects of Fecal Microbiota Transplantation on Ulcerative Colitis in Mice. Dig Dis Sci (2016) 61(8):2262-71. doi: 10.1007/s10620-016-4060-2

168. Zhou J, Zhou Z, Ji P, Ma M, Guo J, Jiang S. Effect of Fecal Microbiota Transplantation on Experimental Colitis in Mice. Exp Ther Med (2019) 17 (4):2581-6. doi: 10.3892/etm.2019.7263

169. Merrick B, Allen L, Zain NMM, Forbes B, Shawcross DL, Goldenberg SD. Regulation, Risk and Safety of Faecal Microbiota Transplant. Infect Prev Pract (2020) 2(3). doi: 10.1016/j.infpip.2020.100069

170. Dailey FE, Turse EP, Daglilar E, Tahan V. The Dirty Aspects of Fecal Microbiota Transplantation: A Review of its Adverse Effects and
Complications. Curr Opin Pharmacol (2019) 49:29-33. doi: 10.1016/ j.coph.2019.04.008

171. Sun J, Xu J, Ling Y, Wang F, Gong T, Yang C, et al. Fecal Microbiota Transplantation Alleviated Alzheimer's Disease-Like Pathogenesis in APP/ PS1 Transgenic Mice. Transl Psychiatry (2019) 9(1):189. doi: 10.1038/ s41398-019-0525-3

172. Jeong HK, Ji K, Min K, Joe EH. Brain Inflammation and Microglia: Facts and Misconceptions. Exp Neurobiol (2013) 22(2):59-67. doi: 10.5607/ en.2013.22.2.59

173. Kim MS, Kim Y, Choi H, Kim W, Park S, Lee D, et al. Transfer of a Healthy Microbiota Reduces Amyloid and Tau Pathology in an Alzheimer's Disease Animal Model. Gut (2020) 69(2):283-94. doi: 10.1136/gutjnl2018-317431

174. Hartstra AV, Schuppel V, Imangaliyev S, Schrantee A, Prodan A, Collard D, et al. Infusion of Donor Feces Affects the Gut-Brain Axis in Humans With Metabolic Syndrome. Mol Metab (2020) 42:101076. doi: 10.1016/ j.molmet.2020.101076

175. Ley RE, Backhed F, Turnbaugh P, Lozupone CA, Knight RD, Gordon JI. Obesity Alters Gut Microbial Ecology. Proc Natl Acad Sci U S A (2005) 102 (31):11070-5. doi: 10.1073/pnas.0504978102

176. Nguyen TL, Vieira-Silva S, Liston A, Raes J. How Informative is the Mouse for Human Gut Microbiota Research? Dis Model Mech (2015) 8(1):1-16. doi: $10.1242 / \mathrm{dmm} .017400$

177. Zhang X, Zhong H, Li Y, Shi Z, Ren H, Zhang Z, et al. Sex-and Age-Related Trajectories of the Adult Human Gut Microbiota Shared Across Populations of Different Ethnicities. Nat Aging (2021) 1(1):87-100. doi: 10.1038/s43587020-00014-2

178. Markle JG, Frank DN, Mortin-Toth S, Robertson CE, Feazel LM, RolleKampczyk U, et al. Sex Differences in the Gut Microbiome Drive HormoneDependent Regulation of Autoimmunity. Science (2013) 339(6123):1084-8. doi: $10.1126 /$ science. 1233521

179. Elderman M, Hugenholtz F, Belzer C, Boekschoten M, van Beek A, de Haan B, et al. Sex and Strain Dependent Differences in Mucosal Immunology and Microbiota Composition in Mice. Biol Sex Differ (2018) 9(1):26. doi: 10.1186/ s13293-018-0186-6

180. Callahan MJ, Lipinski WJ, Bian F, Durham RA, Pack A, Walker LC. Augmented Senile Plaque Load in Aged Female Beta-Amyloid Precursor Protein-Transgenic Mice. Am J Pathol (2001) 158(3):1173-7. doi: 10.1016/ S0002-9440(10)64064-3

181. Jiao SS, Bu XL, Liu JH, Zhu C, Wang QH, Shen LL, et al. Sex Dimorphism Profile of Alzheimer's Disease-Type Pathologies in an APP/PS1 Mouse Model. Neurotox Res (2016) 29(2):256-66. doi: 10.1007/s12640-0159589-x

182. Manji Z, Rojas A, Wang W, Dingledine R, Varvel NH, Ganesh T. 5xfad Mice Display Sex-Dependent Inflammatory Gene Induction During the Prodromal Stage of Alzheimer's Disease. J Alzheimers Dis (2019) 70 (4):1259-74. doi: 10.3233/JAD-180678

183. Granger MW, Franko B, Taylor MW, Messier C, George-Hyslop PS. Bennett Sa. A Tgcrnd8 Mouse Model of Alzheimer's Disease Exhibits Sexual Dimorphisms in Behavioral Indices of Cognitive Reserve. J Alzheimers Dis (2016) 51(3):757-73. doi: 10.3233/JAD-150587

184. Ferretti MT, Iulita MF, Cavedo E, Chiesa PA, Schumacher Dimech A, Santuccione Chadha A, et al. Sex Differences in Alzheimer Disease - the Gateway to Precision Medicine. Nat Rev Neurol (2018) 14(8):457-69. doi: 10.1038/s41582-018-0032-9

185. Goodman AL, Kallstrom G, Faith JJ, Reyes A, Moore A, Dantas G, et al. Extensive Personal Human Gut Microbiota Culture Collections Characterized and Manipulated in Gnotobiotic Mice. Proc Natl Acad Sci USA (2011) 108(15):6252-7. doi: 10.1073/pnas.1102938108

186. Park JC, Im SH. Of Men in Mice: The Development and Application of a Humanized Gnotobiotic Mouse Model for Microbiome Therapeutics. Exp Mol Med (2020) 52(9):1383-96. doi: 10.1038/s12276-020-0473-2

187. Wang Y, Ulland TK, Ulrich JD, Song W, Tzaferis JA, Hole JT, et al. TREM2Mediated Early Microglial Response Limits Diffusion and Toxicity of Amyloid Plaques. J Exp Med (2016) 213(5):667-75. doi: 10.1084/ jem.20151948

188. Yuan P, Condello C, Keene CD, Wang Y, Bird TD, Paul SM, et al. Trem2 Haplodeficiency in Mice and Humans Impairs the Microglia Barrier 
Function Leading to Decreased Amyloid Compaction and Severe Axonal Dystrophy. Neuron (2016) 90(4):724-39. doi: 10.1016/j.neuron.2016.05.003

189. Shi Y, Holtzman DM. Interplay Between Innate Immunity and Alzheimer Disease: APOE and TREM2 in the Spotlight. Nat Rev Immunol (2018) 18 (12):759-72. doi: 10.1038/s41577-018-0051-1

190. Shi Y, Yamada K, Liddelow SA, Smith ST, Zhao L, Luo W, et al. ApoE4 Markedly Exacerbates Tau-Mediated Neurodegeneration in a Mouse Model of Tauopathy. Nature (2017) 549(7673):523-7. doi: 10.1038/nature24016

191. Nicastro L, Tükel Ç. Bacterial Amyloids: The Link Between Bacterial Infections and Autoimmunity. Trends Microbiol (2019) 27(11):954-63. doi: 10.1016/j.tim.2019.07.002

192. Zhao Y, Dua P, Lukiw W. Microbial Sources of Amyloid and Relevance to Amyloidogenesis and Alzheime's Disease (Ad). J Alzheimer's Dis Parkinsonism (2015) 5:177. doi: 10.4172/2161-0460.1000177

193. Friedland RP. Mechanisms of Molecular Mimicry Involving the Microbiota in Neurodegeneration. J Alzheimers Dis (2015) 45(2):349-62. doi: 10.3233/ JAD-142841

194. Friedland RP, Chapman MR. The Role of Microbial Amyloid in Neurodegeneration. PloS Pathog (2017) 13(12):e1006654. doi: 10.1371/ journal.ppat.1006654

195. Chen SG, Stribinskis V, Rane MJ, Demuth DR, Gozal E, Roberts AM, et al. Exposure to the Functional Bacterial Amyloid Protein Curli Enhances Alpha-Synuclein Aggregation in Aged Fischer 344 Rats and Caenorhabditis Elegans. Sci Rep (2016) 6:34477. doi: 10.1038/srep34477

196. Lundmark K, Westermark GT, Olsén A, Westermark P. Protein Fibrils in Nature can Enhance Amyloid Protein A Amyloidosis in Mice: Cross-seeding as a Disease Mechanism. Proc Natl Acad Sci U S A (2005) 102(17):6098-102. doi: 10.1073/pnas.0501814102

197. Zhou Y, Smith D, Leong BJ, Brännström K, Almqvist F, Chapman MR. Promiscuous Cross-Seeding Between Bacterial Amyloids Promotes Interspecies Biofilms. J Biol Chem (2012) 287(42):35092-103. doi: 10.1074/ jbc.M112.383737

198. Chung YW, Gwak HJ, Moon S, Rho M, Ryu JH. Functional Dynamics of Bacterial Species in the Mouse Gut Microbiome Revealed by Metagenomic and Metatranscriptomic Analyses. PloS One (2020) 15(1):e0227886. doi: 10.1371/journal.pone.0227886

199. Yooseph S, Sutton G, Rusch DB, Halpern AL, Williamson SJ, Remington K, et al. The Sorcerer Ii Global Ocean Sampling Expedition: Expanding the Universe of Protein Families. PloS Biol (2007) 5(3):e16. doi: 10.1371/ journal.pbio.0050016

Conflict of Interest: The authors declare that the research was conducted in the absence of any commercial or financial relationships that could be construed as a potential conflict of interest.

Copyright (C) 2021 van Olst, Roks, Kamermans, Verhaar, van der Geest, Muller, van der Flier and de Vries. This is an open-access article distributed under the terms of the Creative Commons Attribution License (CC BY). The use, distribution or reproduction in other forums is permitted, provided the original author(s) and the copyright owner(s) are credited and that the original publication in this journal is cited, in accordance with accepted academic practice. No use, distribution or reproduction is permitted which does not comply with these terms. 